\title{
Congenital myasthenic syndromes
}

\author{
Josef Finsterer
}

\begin{abstract}
Objectives: Congenital myasthenic syndromes (CMSs) are a genotypically and phenotypically heterogeneous group of neuromuscular disorders, which have in common an impaired neuromuscular transmission. Since the field of CMSs is steadily expanding, the present review aimed at summarizing and discussing current knowledge and recent advances concerning the etiology, clinical presentation, diagnosis, and treatment of CMSs.

Methods: Systematic literature review.

Results: Currently, mutations in 32 genes are made responsible for autosomal dominant or autosomal recessive CMSs. These mutations concern 8 presynaptic, 4 synaptic, 15 post-synaptic, and 5 glycosilation proteins. These proteins function as ion-channels, enzymes, or structural, signalling, sensor, or transporter proteins. The most common causative genes are CHAT, COLQ, RAPSN, CHRNE, DOK7, and GFPT1. Phenotypically, these mutations manifest as abnormal fatigability or permanent or fluctuating weakness of extra-ocular, facial, bulbar, axial, respiratory, or limb muscles, hypotonia, or developmental delay. Cognitive disability, dysmorphism, neuropathy, or epilepsy are rare. Low- or high-frequency repetitive nerve stimulation may show an abnormal increment or decrement, and SF-EMG an increased jitter or blockings. Most CMSs respond favourably to acetylcholine-esterase inhibitors, 3,4-diamino-pyridine, salbutamol, albuterol, ephedrine, fluoxetine, or atracurium.
\end{abstract}

Conclusions: CMSs are an increasingly recognised group of genetically transmitted defects, which usually respond favorably to drugs enhancing the neuromuscular transmission. CMSs need to be differentiated from neuromuscular disorders due to muscle or nerve dysfunction.

Keywords: Myasthenic syndrome, Myasthenia, Repetitive nerve stimulation, Fatigue, Weakness, Hereditary, Genes, Mutation

\section{Introduction}

Congenital myasthenic syndromes (CMS) are a heterogeneous group of early-onset genetic neuromuscular transmission disorders due to mutations in proteins involved in the organisation, maintenance, function, or modification of the motor endplate (endplate myopathies) [1,2] (Fig. 1). CMS are clinically characterised by abnormal fatigability, or transient or permanent weakness of extra-ocular, facial, bulbar, truncal, respiratory, or limb muscles. Onset of endplate myopathy is intrauterine, congenital, in infancy, or childhood, and rarely in adolescence. Severity ranges from mild, phasic weakness, to disabling, permanent muscle weakness, respiratory insufficiency, and early death. All subtypes of CMS share the clinical features of fatigability and muscle

Correspondence: fifigs1@yahoo.de

Krankenanstalt Rudolfstiftung, Messerli Institute, Veterinary University of Vienna, Postfach 20, 1180 Vienna, Austria weakness, but age of onset, presenting symptoms, and response to treatment vary depending on the molecular mechanism that results from the underlying genetic defect. The term CMS is misleading since not all CMS are congenital.

Aims of the present review were to summarise and discuss previous and recent findings concerning the genotype, phenotype, diagnosis, treatment, and outcome of CMS.

\section{Methods}

Data for this review were identified by searches of MEDLINE for references of relevant articles. Search terms used were "congenital myasthenic syndrome", "endplate", or "mutation", combined with all gene names so far associated with CMS. Results of the search were screened for potentially relevant studies by application of inclusion and exclusion criteria for the full texts of the relevant studies. Randomized controlled trials 
(RCTs), observational studies with controls, case series, and case reports were included. Only original articles about humans, and published between 1966 and 2017 were included. Reviews, editorials, and letters were not considered. Reference lists of retrieved studies were checked for reports of additional studies. Websites checked for additional, particularly genetic information and for assessing the pathogenicity of CMS mutations were the following:

Neuromuscular homepage: https://neuromuscularwu. stl.edu/

Genetics home reference: https://ghr.nlm.nih.gov/condition/congenital-myasthenic-syndrome

National Organisation for Rare Disorders: https://rarediseases.org/rare-diseases/congenital-myasthenic-syndromes/.

\section{Results}

\section{History}

The first case of a patient with CMS was reported in 1977 by Engel et al. [3]. The first mutation associated with CMS was reported in the CHRNE gene by Gomez et al. in 1995 [4]. The first molecular genetic defect resulting in a presynaptic congenital myasthenic syndrome has been reported by Ohno in 2001 [5]. Detection dates of mutations in any of the 32 CMS genes reported in the literature are listed in Table 1.

\section{Classification}

CMS may be classified according to various different criteria. According to the mode of inheritance, CMS may be classified as autosomal dominant (AD), autosomal recessive (AR), as de novo, or as either AD or AR [6]. CMS can be also classified according to the mutated protein (Table 2). Following this classification criterion, 32 different types of CMS can be currently differentiated (Table 2). A third scheme differentiates CMS due to a presynaptic, synaptic or post-synaptic pathology. A fourth category refers to CMS due to glycosylation defects. Furthermore, CMS may be classified according to the function of the mutated protein (e.g. enzyme, structural protein, pore protein). Another possibility to classify CMS is the type of mutation such as point mutations (missense or truncating (frameshift, splice site, nonsense)), deletions, duplications, indels, or insertions. According to the long-term course, CMS may be classified as progressive, fluctuating, or regressive [7].

\section{Frequency}

Concerning the frequency of CMS only limited data are available since most of the current knowledge has been obtained by reports of isolated cases [8]. According to a recent review, the prevalence of CMS is estimated as 1/ 10 that of myasthenia gravis, which is $25-125 / 1000000$
[6]. In a recent study on the frequency of autoimmune myasthenia and genetic myasthenia in patients under $18 \mathrm{y}$ of age, the prevalence of CMS in Great Britain was calculated as $9.2 / 1000000$ but varies considerably between the regions between 2.8 and 14.8/1000000 [9]. In the Brasilian state of Parana the prevalence of CMS was estimated as 0.18/100000 [10]. Most likely, these prevalence figures are underestimations because CMS may go undetected if mixed up with one of the many differential diagnoses or if manifesting only with mild symptoms. In several regions worldwide local increases of certain mutations have been detected. In the Roma population of South-East Europe an increased frequency of the c.1327delG variant in the CHRNE gene has been reported [11]. Similarly, an increased prevalence of the variant c.1353duplG in the CHRNE gene has been reported in Algeria and Tunisia [12]. In Spain and Portugal the CHRNE variant c.130dupC is highly prevalent. CHRNE-related CMS is generally regarded as the most common of the CMS. In Western or central Europe the RAPSN variant c. $264 \mathrm{C}>\mathrm{A}$ and the $D O K 7$ variant c.1124_1172dupTGCC are highly prevalent. Concerning the frequency of the 32 CMS subtypes, mutations in the CHRNE gene are the most frequent, accounting for $30-50 \%$ of the CMS cases, a figure which varies significantly between different ethnia [13]. Mutations in the CHRNE gene result in acetylcholine-receptor deficiency or abnormal channel kinetics [14]. The second most frequent defect is that in the RAPSN gene accounting for $15-20 \%$ of the CMS cases. The third and fourth most frequent CMS subtypes are COLQ and DOK7 variants accounting for $10-15 \%$ of the CMS cases. Mutations in the CHAT gene account for $4-5 \%$ of the CMS cases [6]. Mutations in GFPT1 can be found in 2\% of the CMS cases. However, these figures may vary between countries and regions under investigation. In a study of 34 CMS families from Israel the genes most frequently mutated were RAPSN $(n=13), C O L Q(n=11)$, and CHRNE $(n=7)$ [15]. All other mutated proteins may contribute with less than $1 \%$ of the CMS cases to the general group of CMS. About $75 \%$ of the CMS cases are due to mutations in genes that encode different subunits of the acetylcholine receptor (CHRNA1, CHRNB1, CHRND, CHRNE) or proteins important to maintain the structure or function of the NMJ, such as MUSK, RAPSN or DOK7 [16, 17]. The most common causative genes are CHAT, $C O L Q$, RAPSN, CHRNE, DOK7, and GFPT1.

\section{Mutated proteins}

Currently, 32 proteins located on the presynaptic, synaptic or post-synaptic part of the motor endplate/neuromuscular junction (NMJ) or proteins undergoing abnormal glycosylation have been reported to be 
Table 1 First reports of mutations in any of the 32 CMS genes [142]

\begin{tabular}{|c|c|c|c|}
\hline Gene & Year of first report & NOPR\# & Reference for 1st description \\
\hline$\overline{\text { COLQ }}$ & 1998 & $>115$ & [136] \\
\hline CHRNE & 2000 & 97 & {$[60]$} \\
\hline CHAT & 2001 & 46 & {$[5]$} \\
\hline SCN4A & 2003 & 3 & [96] \\
\hline RAPSN & 2003 & 84 & {$[137]$} \\
\hline MUSK & 2004 & 9 & [138] \\
\hline CHRND & 2006 & 4 & {$[58]$} \\
\hline CHRNG & 2006 & 17 & {$[68]$} \\
\hline DOK7 & 2006 & $>50$ & [139] \\
\hline CHRNA1 & 2008 & 6 & [54] \\
\hline LAMB2 & 2009 & 1 & [49] \\
\hline AGRN & 2009 & 12 & [140] \\
\hline CHRNB1 & 2010 & 3 & {$[10]$} \\
\hline PLEC1 & 2010 & 3 & {$[104]$} \\
\hline GFPT1 & 2011 & 29 & [141] \\
\hline DPAGT1 & 2012 & 12 & [124] \\
\hline ALG2 & 2013 & $5+1$ family & {$[108,122]$} \\
\hline ALG14 & 2013 & 7 & {$[108]$} \\
\hline LRP4 & 2014 & 3 & {$[90,92]$} \\
\hline PREPL & 2014 & 1 & [93] \\
\hline SNAP25 & 2014 & 1 & [30] \\
\hline SYT2 & 2014 & 2 families & [33] \\
\hline SLC25A1 & 2014 & 3 & [107] \\
\hline COL13A1 & 2015 & 3 & [52] \\
\hline GMPPB & 2015 & 13 & [109] \\
\hline SLC18A3 & 2016 & 3 families & [29] \\
\hline SLC5A7 & 2016 & 7 families & [21] \\
\hline MYO9A & 2016 & 3 & [86] \\
\hline MUNC13-1 & 2016 & 1 & [36] \\
\hline VAMP1 & 2017 & 4 & [31] \\
\hline LAMA5 & 2017 & 1 & [51] \\
\hline SYB1 & 2017 & 1 & [7] \\
\hline
\end{tabular}

NOPR: number of patients/families reported so far, \#: since first description (some figures may be imprecise since reporting of patients may overlap between publications)

involved in the various types of CMS. Eight proteins are associated with presynaptic CMS, four with synaptic CMS, fifteen with post-synaptic CMS, and five with glycosylation defects. Proteins affected in CMS have different functions, such as ion channels (AchR, SNC4A), structural proteins (LAMA5, COL13A1, RAPSN, PLEC, COLQ), signalling molecules (AGRN, LRP4, MUSK, DOK7), catalytic enzymes (CHAT, GFPT1, DPAGT1, ALG14, ALG2, GMBBP, PREPL, SLC25A1), sensor proteins (SYT2), or transport proteins (SLC18A3) [18].

\section{Pre-synaptic CMS}

The majority of CMS is caused by defects in post-synaptic proteins but some of the CMSs are also caused by defects of the presynaptic proteins [19]. These include the proteins SLC5A7, CHAT, SLC18A3, SNAP25, VAMP1, SYB1, SYT2, and MUNC13-1 [1, 6]. Presynaptic defects may be further categorised as disorders affecting the axonal transport, disorders affecting the synthesis and recycling of acetylcholine, and disorders affecting the exocytosis of synaptic vesicles. 


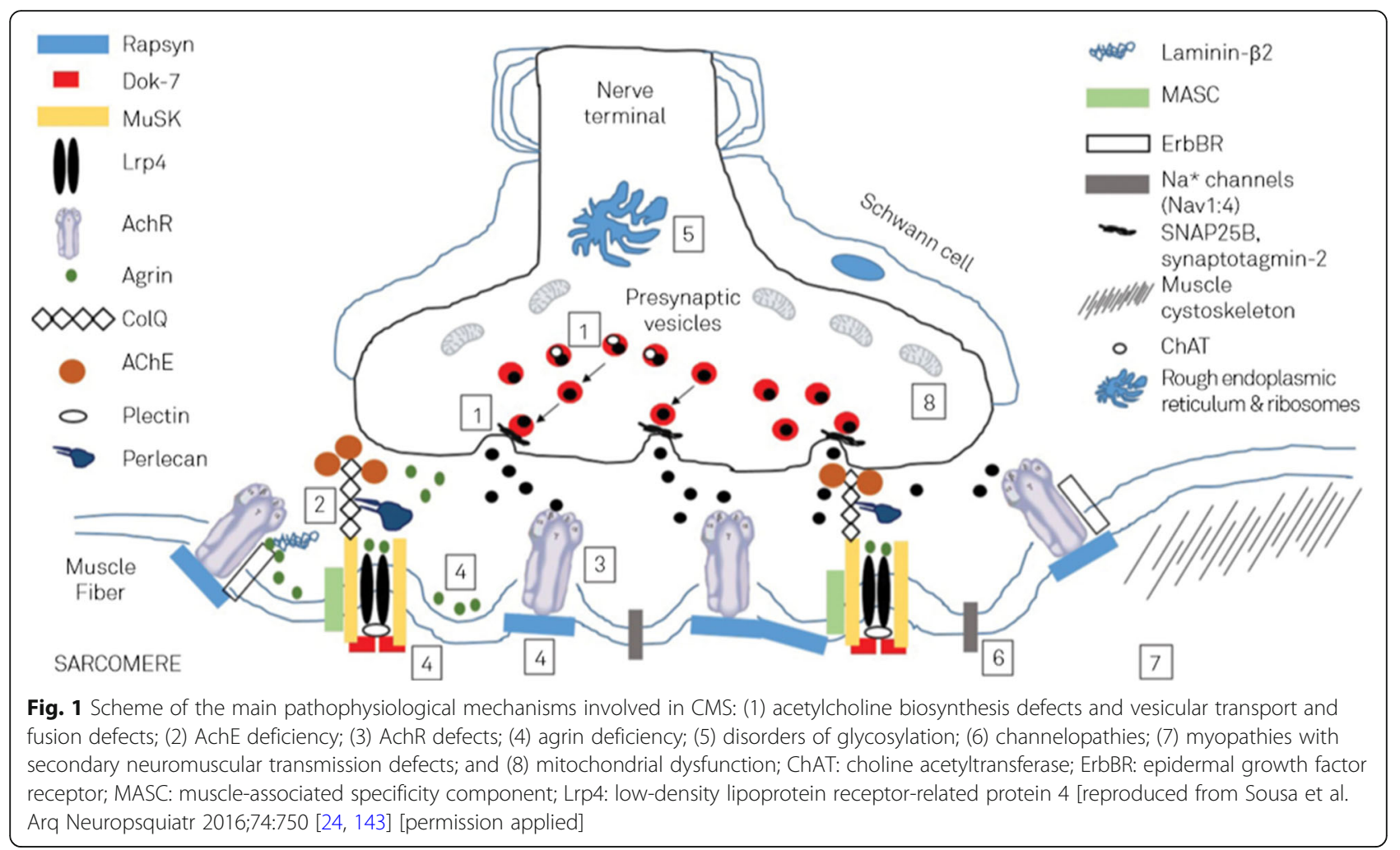

\section{Disorders affecting the axonal transport}

SLC5A7 Recently, mutations in the presynaptic, Na-dependent, high-affinity choline transporter-1 (CHT) encoded by the $S L C 5 A 7$ gene have been identified as a rare cause of CMS [20]. Mutations in this gene also cause allelic AD forms of distal motor neuropathy [20]. Patients with SLC5A7-related CMS present with severe muscle weakness, ranging from lethal antenatal arthrogryposis and severe hypotonia to a neonatal form of CMS with episodic apneas. The prognosis of apneas is more favourable if patients respond to AchEI [20]. In another family, patients presented with severe neuro-developmental delay with cerebral atrophy [21]. Low-frequency repetitive nerve stimulation (LF-RNS) usually shows a decrement but sometimes only after previous high-frequency RNS (HF-RNS) during 10s with $20 \mathrm{~Hz}$ [20]. All patients reported responded favourably to AchEI and one patient also to salbutamol [20].

\section{Disorders affecting the synthesis and recycling of acetylcholine}

Chat The CHAT gene encodes for the cholin acetyltransferase, which promotes the resynthesis of acetylcholine [22]. Clinically, patients present with ptosis, limb muscle weakness, easy fatigability, and recurrent episodes of potentially fatal apnea [22]. Episodes of apnea have an abrupt onset but may be triggered by physical or emotional stress or acute illness.
Cerebral hypoxia/ischemia during apneic episodes may secondarily result in global developmental delay with delayed myelination and signs of hypoxicischemic injury on cerebral imaging [23]. Apnea may be present already at birth or may rarely begin during childhood or early adulthood [24]. Infections or stress may lead to life-threatening failure of neuromuscular transmission [25]. Muscle MRI is usually normal [26]. Ultrastructural investigations of the NMJ may be non-informative [22]. In-vitro microelectrode studies performed in biopsied muscle may show moderate reduction of quantal release [22]. AchEI may be beneficial for mild symptoms [27] but may not prevent the occurrence of apneic episodes [23]. Some patients may require permanent ventilation [25]. Despite the application of AchEI, permanent proximal muscle weakness may develop and may lead to wheelchairdependency [28].

SLC18A3 The SLC18A3 gene encodes the vesicular acetylcholine transporter VAchT [19]. VAchT loads newly synthesised acetylcholine from the neuronal cytoplasm into synaptic vesicles [19, 29]. SLC18A3-related CMS have been reported in only three families [19, 29]. Index cases from the first two families presented with ptosis, ophthalmoparesis, fatigue, weakness, and apneic crises [29]. Interestingly, muscle manifestations in these patients deteriorated in cold water (paramyotonia) [29]. 
Table 2 Genes mutated in CMS

\begin{tabular}{|c|c|c|c|c|c|}
\hline Gene & Chromosome & $\mathrm{MOI}$ & LD & OOCM & PCMS (\%) \\
\hline AGRN & $1 p 36.33$ & $A R$ & post & con, inf & $<1$ \\
\hline ALG2 & $9 q 22.33$ & $A R$ & glyc & con, inf & $<1$ \\
\hline ALG14 & $1 \mathrm{p} 21.3$ & $A R$ & glyc & con, child & $<1$ \\
\hline CHAT & $10 q 11.23$ & $A R$ & pre & con, inf & $4-5$ \\
\hline CHRNA1 & $2 \mathrm{q} 31.1$ & $A D / A R$ & post & con, adult & $<1$ \\
\hline CHRNB1 & 17p13.1 & AF/AR & post & $\inf$ & $<1$ \\
\hline CHRND & $2 \mathrm{q} 37.1$ & $A D / A R$ & post & $\inf$ & $<1$ \\
\hline CHRNE & $17 p 13.2$ & $\mathrm{AD} / \mathrm{AR}$ & post & con, inf, child, adult & 50 \\
\hline CHRNG & $2 \mathrm{q} 37.1$ & $A R$ & post & con & uk \\
\hline COL13A1 & $10 \mathrm{q} 22.1$ & AR & post & con & $<1$ \\
\hline COLQ & $3 p 24.2$ & $A R$ & syn & con, inf, child & $10-15$ \\
\hline DOK7 & $4 p 16.3$ & $A R$ & post & con, inf, child, adol, adult & $10-15$ \\
\hline DPAGT1 & $11 q 23.3$ & $A R$ & glyc & inf, adol & $<1$ \\
\hline GFPT1 & $2 p 13.3$ & $A R$ & glyc & con, inf, child, adult & 2 \\
\hline GMPPB & $3 p 21.31$ & $A R$ & glyc & con & $<1$ \\
\hline LAMA5 & $20 q 13.33$ & uk & pre & con & $<1$ \\
\hline LAMB2 & $3 p 21.31$ & $A R$ & syn & con & $<1$ \\
\hline LRP4 & $11 \mathrm{p} 11.2$ & $A R$ & post & con & $<1$ \\
\hline MUNC13-1 & 19 & $A R$ & pre & inf & $<1$ \\
\hline MUSK & $9 q 31.3$ & $A R$ & post & con & $<1$ \\
\hline MYO9A & $15 q 23$ & $A R$ & post & con & $<1$ \\
\hline PLEC & $8 q 24.3$ & $A R$ & post & con & $<1$ \\
\hline PREP1 & $2 p 21$ & $A R$ & post & con & $<1$ \\
\hline RAPSN & $11 p 13-q 1$ & $A R$ & post & con, inf, child, adol, adult & $10-20$ \\
\hline SCN4A & $17 q 23.3$ & $A R$ & post & inf & $<1$ \\
\hline SLC18A3 & $10 q 11.23$ & $A R$ & pre & con, inf & $<1$ \\
\hline SLC25A1 & $22 q 11.21$ & $A R$ & post & inf & $<1$ \\
\hline SLC5A7 & $2 q 12.3$ & $A D$ & pre & con, inf & $<1$ \\
\hline SNAP25 & 20p12.2 & $A D$ & pre & con & $<1$ \\
\hline SYB1 & $12 p$ & uk & pre & inf & $<1$ \\
\hline SYT2 & $1 \mathrm{q} 32.1$ & $A D$ & pre & child & $<1$ \\
\hline VAMP1 & $12 p 13.21$ & $A R$ & pre & con & $<1$ \\
\hline
\end{tabular}

$\mathrm{MO}$ mode of inheritance, $L D$ localisation of defect, pre: presynaptic, syn: synaptic, post: post-synaptic, glyc: glycosylation defect, OOCM onset of clinical manifestations, con congenital, inf infantile, child childhood, adol adolescence, adult: adulthood PCMS prevalence of various subtypes, ${ }^{\text {a }}$ : according to [6], uk unknown

One of the patients also had learning difficulties and left ventricular systolic dysfunction [29]. The two patients from family 3 presented with respiratory failure since birth requiring mechanical ventilation [19]. Index patients of family 1 and 3 showed prominent decrement on LF-RNS followed by a prolonged period of postactivation exhaustion [29]. In one patient the decremental response could be unmasked only after isometric contraction, a well-recognised feature of presynaptic disease [29]. AchEI were only moderately effective.

\section{Disorders affecting the exocytosis of synaptic vesicles}

SNAP25 SNAP25 encodes a "soluble $N$-ethyl-maleimide sensitive fusion (NSF) attachment" (SNARE) protein essential for exocytosis of synaptic vesicles from nerve terminals and of dense-core vesicles from endocrine cells [30]. Ca++-triggered exocytosis is initiated when synaptobrevin, attached to synaptic vesicles (v-SNARE), assembles with SNAP25B and syntaxin, anchored in the presynaptic membrane (t-SNAREs) into an $\alpha$-helical coiled-coil, held together by hydrophobic interactions [30]. Mutations in the SNAP25 gene result in inhibition 
of synaptic vesicle exocytosis [30]. SNAP25-related CMS has been reported only in a single female who presented with myasthenia, congenital contractures, cortical hyperexcitability, cerebellar ataxia, and severe intellectual disability [30]. In this patient neuromuscular transmission was compromised due to reduced quantal release.

VAMP1 The VAMP1 gene encodes for a presynaptic protein, which is crucial for vesicle fusion at the presynaptic membrane [31]. So far, VAMP1-related CMS has been reported in a Kuwaiti and an Israeli family [31]. The two patients from the Kuwaiti family presented shortly after birth with hypotonia, muscle weakness, feeding difficulties requiring gavage feeding, delayed motor development, and ophthalmoparesis [31]. One patient had joint contractures [31]. The two patients from the Israeli family presented with severe congenital hypotonia and muscle weakness, feeding difficulties requiring percutaneous entero-gastrostomy (PEG) implantation, and severely delayed developmental milestones [31]. One of them additionally had joint laxity and kyphoscoliosis, the other one had knee contractures and respiratory insufficiency [31]. Both patients were unable to generate antigravity postures or movements [31]. Electrophysiologic examination revealed severely low compound muscle action potentials (CMAPs) and presynaptic impairment [31]. Both Israeli patients profited from pyridostigmine [31].

SYB1 SYB1 encodes for the SNARE protein synaptobrevin, which is essential for synaptic vesicle exocytosis [7]. Mutations in SYB1 have been reported in a single patient with CMS [7]. The female presented at birth with marked hypotonia and feeding difficulties [7]. At age 2y, severe muscle weakness, wasting, and mild ophthalmoparesis developed [7]. LF-RNS was followed by a decremental response, and $20 \mathrm{~Hz}$ stimulation during $5 \mathrm{~s}$ increased the CMAP-amplitude up to 9-fold [7]. Pyridostigmine had a moderate beneficial effect [7]. Over the years, muscle weakness slightly improved such that she could sit unaided but slurred speech and inability to swallow persisted [7]. She died from respiratory failure precipitated by infection at age $14 y$ [7].

SYT2 SYT2 encodes the presynaptic protein synaptotagmin that interacts with SNAP25 and is involved in the calcium-evoked acetylcholine release. SYT2-related CMS has been reported in two families [32, 33]. Clinically, patients presented with prominent muscle weakness of the lower limbs and areflexia. Motor neuropathy has been another phenotypic feature. Various family members presented with foot deformities (pes cavus (hollow feet), hammertoes, pes planus, clawing), hyperlaxity, hip dysplasia, hypotonia, diffuse limb weakness and wasting, and mild ptosis [32]. LF-RNS evoked a decremental response in several family members. Maximal voluntary contraction for 10s (facilitation) resulted in a marked increase of the CMAP [32]. 3,4-DAP was more effective than pyridostigmine [32].

MUNC13-1 MUNC13-1 acts as a master regulator of neurotransmitter release, mediating docking-priming of synaptic vesicles and various presynaptic plasticity processes [34]. MUNC13-1 bridges the vesicle and plasma membranes from the periphery of the membrane-membrane interface [34]. In the inactive state, MUNC13-1 locks syntaxin, another SNARE protein, in a folded state [35]. Upon Ca2+ entry into the nerve terminal, MUNC13-1 unlocks syntaxin by displacing MUNC18 allowing syntaxin to interact with synaptobrevin and SNAP25B to effect vesicle exocytosis [35]. Mutations in MUNC13-1 have been reported only in a single patient. In a 2 yo girl with generalised hypotonia, feeding difficulties, respiratory insufficiency, microcephaly, callosal atrophy, facial dysmorphism, variable ptosis, quadruparesis, scoliosis, flexion contractures, and paroxysmal EEG activity, whole exome sequencing (WES) revealed the homozygous mutation c.304C $>\mathrm{T}$ in the MUNC13-1 gene [36]. The CMAP was low at rest, and LF-RNS revealed a decrement of 20-40\% and HF-RNS an increment between 0.8 and $4 \mathrm{mV}$ [36]. Pyridostigmine and 3,4-DAP were only partially effective [36].

Synaptic CMS Four of the 32 subtypes of CMS are due mutations in genes encoding synaptic proteins. These include COLQ, LAMB2, LAMA5, and COL13A1 [1].

COLQ COLQ encodes a multidomain functional protein of the NMJ, crucial for anchoring AChE to the basal lamina and accumulating $\mathrm{AChE}$ at the NMJ [37]. COLQ-related CMS may not only be due to point mutations, deletions or duplications, but also due to copy number variant mutations (deletion or duplication of the entire gene) [21]. Mutations in COLQ cause AchE deficiency. Clinically, COLQ-related CMS presents with a broad range of features and severity from mild muscle manifestations, such as gait disturbance with independent ambulation and mild respiratory insufficiency, to wheel-chair boundness, or early death [38]. Usually, however, the clinical manifestations are severe. Particularly the axial muscles can be severely affected and the ocular muscles are usually spared [1]. Several patients with a limb-girdle muscular dystrophy (LGMD)-like phenotype have been reported [39]. Some patients may experience short- or long-term relapses, being triggered by AchEI, infections, puberty, or pregnancy [40]. 
Occasionally, the phenotype includes ptosis, ophthalmoparesis, or facial diplegia. The pupillary response may be slowed. Some patients may present with respiratory failure at birth or later in the course [41, 42]. Some patients may present with severe scoliosis [43]. In two patients, isolated vocal cord paralysis has been reported as initial manifestation, which did not respond to pyridostigmine, mildly to 3,4-DAP, but favourably to ephedrine [42]. Rarely, microcephaly has been reported [41]. Interestingly, heterozygote carriers can present with congenital ptosis [44]. Single nerve stimuli may evoke double responses. Muscle MRI may be normal [26]. Muscle biopsy may show mild fibre-size variation and marked type-I-muscle fiber predominance [45]. Some patients may show dystrophic features and dystrophin deficiency [45]. Biochemical investigations may reveal complex-I-deficiency [45]. Pyridostigmine is ineffective or even detrimental [46]. However, several patients have responded favourably to ephedrine [3, 47] and some to salbutamol [48].

LAMB2 The LAMB2 gene encodes for the laminin-beta-2 protein, which plays a major role in the development of the NMJ. The gene is ubiquitously expressed but manifests mainly at the NMJ. LAMB2-related CMS has been reported only in a single 22yo female so far [49]. The patient presented clinically with episodes of respiratory distress, delayed motor milestones, and persistently constricted pupils and nephrotic syndrome (Pierson syndrome), requiring kidney transplantation [49]. Later in the course, the patient developed ptosis, ophthalmoparesis, and scoliosis [49]. LF-RNS was decremental, which became more pronounced at $10 \mathrm{~Hz}$ stimulation [49]. Microelectrode recordings revealed profound reduction of the quantal content of endplate potentials [49]. AchEI caused deterioration, such that the patient required ventilatory support [49]. On the contrary, the patient responded favourably to ephedrine [49].

LAMA5 The LAMA5 gene encodes for the protein laminin-A5 involved in the maintenance and function of the extracellular matrix [50]. Laminin-A5 is a major component of the basal membrane and cooperates with growth factors and matrix-dependent receptors in cell proliferation and differentiation [50]. LAMA5-related CMS has been reported only in a single patient [51]. The female presented at age $24 \mathrm{y}$ with muscle weakness, myopia, and facial tics [51]. Cerebral MRI showed mild volume loss and periventricular T2-hyperintensities [51]. LF-RNS evoked a decrement of $55 \%$ but a $250 \%$ increment after 10s of maximal contraction [51]. Endplate studies identified profound reduction of the endplate potential quantal content and endplates with normal post-synaptic folding that were denervated or innervated by small nerve terminals [51].

COL13A1 The COL13A1 gene encodes the $\alpha$-chain of an atypical non-fibrillar collagen with a single transmembrane domain [52]. COL13A1 is localised to the NMJ, where it is responsible for clustering of the AchR during myotube differentiation [52]. Mutations in this gene manifest clinically as CMS, which has been reported in three patients ( 2 females, 1 male) from two families [52]. Two of these patients manifested with congenital respiratory insufficiency, bulbar weakness, or facial weakness. All three patients presented with feeding difficulties, ptosis, limb weakness, and dysmorphism [52]. Two patients each presented with spinal stiffness or distal joint laxity, and one patient with ophthalmoparesis and cognitive impairment. Two showed a decremental response to RNS and two an increased jitter [52]. Two required non-invasive positive pressure ventilation (NIPPV). In two patients pyridostigmine was ineffective. Salbutamol respectively 3,4-DAP was beneficial [52].

\section{Post-synaptic disorders}

Fifteen of the CMS subtypes are due to mutations in genes encoding post-synaptic proteins. These include CHRNA1, CHRNB1, CHRND, CHRNE, CHRNG, DOK7, MUSK, MYO9A, AGRN, LRP4, PREP1, SCN4A, RAPSN, PLEC, and SLC25A1. Thus, post-synaptic CMSs represent the vast majority of the CMS subtypes. Post-synaptic CMS are subdivided into primary AchR deficiency, kinetic abnormalities of the AChR, and defects within the AchR-clustering pathway.

\section{Primary AchR deficiency}

CHRNA1 The CHRNA1 gene encodes the $\alpha$-subunit of the nicotinergic, post-synaptic AchR. CHRNA1 mRNA undergoes alternative splicing and two splice variants (P3A- and P3A+) are produced [53]. Mutations in CHRNA1 result in imbalance between the two splice variants with an increase in P3A+. CHRNA1 mutations reduce the number of $A c h R$ at the post-synaptic membrane [54]. The pattern of inheritance is AD if CHRNA1 mutations cause a slow channel CMS (SCCMS) or AR in case of primary AchR-deficiency [54]. The first CHRNA1-related CMS were reported in 2008 [54] (Table 1 ). Patients presented already prenatally with growth retardation, reduced movements, edema, contractures, and postnatally with dysmorphism, muscle wasting, scoliosis, contractures, and pterygia [55]. Concerning the frequency of CHRNA1 mutations, they were found only in a single of 18 Brasilian families with CMS [10]. CHRNA1-related CMS seems to respond favourably to AchEI [54]. Antisense oligonucleotides (AONs) have been shown to restore the balance between the two 
splice variants and are thus expected to be beneficial in patients carrying such mutations [53].

CHRNB1 The CHRNB1 gene encodes for the $\beta$-subunit of the nicotinergic, post-synaptic AchR. The first mutations in CHRNB1 causing CMS were reported in a Brazilian study in 2008 [10] (Table 1). The first patient published was a 28 yo male manifesting since birth with ptosis, ophthalmoparesis, dysphagia, proximal limb muscle weakness, scapular winging, weakness of axial muscles, wasting, and scoliosis [10]. He showed a decremental response to RNS, had double discharges, and a myopathic EMG. The course was progressive but he benefitted from fluoxetine [10]. The second patient carrying a CHRNB1 mutation was a 3wo male manifesting with ptosis, facial weakness, severe hypotonia, and respiratory insufficiency requiring assisted ventilation [56]. The response to LF-RNS was decremental. AchEI were ineffective and he was put on quinidine but was lost to follow-up [56]. In a Spanish study of a CMS cohort, a third patient with a CHRNB1 mutation was identified but no clinical details were provided [57].

CHRND The CHRND gene encodes the $\delta$-subunit of the nicotinergic, post-synaptic AchR. The first mutation in CHRND causing CMS was reported in a German patient with early-onset CMS manifesting with feeding difficulties, moderate, generalised weakness, and recurrent episodes of respiratory insufficiency provoked by infections [58]. The second patient was a 20 yo female with moderate to severe myasthenic manifestations since birth [59]. She had a marked decremental response to LF-RNS. She responded poorly to AchEI but clearly to 3,4-DAP [59]. One of her siblings with a similar presentation had died at age $11 \mathrm{~m}$ [59]. Two further patients were reported in a study of CMS patients from Israel but no clinical details were provided [15].

CHRNE The CHRNE gene encodes for the $\varepsilon$-subunit of the AchR. The first mutation in the CHRNE gene causing a CMS has been reported already in 2000 (Table 1) [60]. Since then various different types of mutations have been reported and it is estimated that up to half of the patients with a CMS carry a CHRNE mutation, thus representing the gene most frequently mutated in CMS [6]. In a study of 64 CMS patients from Spain, CHRNE mutations were detected in $27 \%$ of the patients [57]. In a study of 45 patients from 35 Israeli CMS families, CHRNE mutations were found in 7 kinships [15]. In a study of 23 families with CMS from Maghreb countries, the founder mutation c.1293insG was found in $60 \%$ of these patients [61]. Type and severity of clinical manifestations of CHRNE mutations may vary considerably between affected families. Some patients may present with only ptosis whereas others may present with severe generalised myasthenia [62]. Most patients present at birth with mildly progressive bulbar, respiratory, or generalized limb weakness with ptosis or ophthalmoplegia $[63,64]$. Single patients may die prematurely in infancy from respiratory failure [65]. Some patients may have myasthenic symptoms since birth and achieve ambulation late or not at all [65]. Single patients present with a fluctuating course [57]. Single patients develop severe scoliosis [27]. RNS may be decremental [27] or may be normal [64]. Single-fiber EMG (SF-EMG) may reveal an increased jitter [64]. Some patients may show repetitive CMAPs [27]. Most patients respond favourably to AchEI [61]. However, in some patients pyridostigmine and 3,4-DAP may be ineffective or may worsen the phenotype. Albuterol can be highly effective in single patients [66]. Other patients may profit significantly from salbutamol [14]. Fluoxetine alone may be ineffective but in combination with salbutamol a significant improvement can be achieved [67].

CHRNG The CHRNG gene encodes for the fetal $\gamma$-subunit of the AchR. Mutations in the CHRNG gene cause CMS with multiple ptyerygia (lethal multiple pterygia syndrome (LMPS) or the Escobar variant of multiple pterygia syndrome (EVMPS)) [68]. In a study of seven families with Escobar syndrome (contractions, multiple pterygia, respiratory distress), mutations in the CHRNG gene were detected in 12 family members [68]. The female to male ratio was 7:5. Some patients presented with decreased fetal movements, facial weakness, respiratory distress, arthrogryposis, short stature, kyphosis/scoliosis, dysmorphism, high-arched palate, cleft palate, arachnodactyly, or cryptorchism [68]. None presented with myasthenic manifestations postnatally. CHRNG mutations may be also responsible for the allelic disease fetal akinesia deformation sequence (FADS) [54]. In a study of $46 \mathrm{CMS}$ patients from Spain, five carried a mutation in the CHRNG gene [57]. They all presented with arthrogryposis and delayed motor milestones, and some of them with poor sucking [57]. Interestingly, none of them received drugs usually given for CMS. In a study of three Iranian CHRNG-related CMS patients, no drug treatment was applied [69]. One of the patients presented with short neck, mild axillar pterygia, elbows and knees, joint contractures, clenched hands with thumbs held across palm and club feet (varus). The patient had rockerbottom feet, with almost no movement in ankles. Facial dysmorphism included hemangioma over forehead and nose, strabismus, flat nasal bridge, and downturned corners of mouth [69]. 


\section{Kinetic abnormalities of the $A C h R$}

According to the kinetics of the AChR, two functionally distinct types of CMS are differentiated, fast channel CMS (FCCMS) and SCCMS.

FCCMS FCCMS is characterized by only a short opening time of the AchR. FCCNS is due to loss of function mutations in subunits of the AchR. These mutations cause abnormally brief $\mathrm{AChR}$ channel openings by enhancing the channel closing rate or by curtailing the channel opening rate. [35]. Decrease in AChR affinity for acetylcholine or altered fidelity of channel openings can also cause shortened channel openings [35]. The safety margin of neuromuscular transmission is compromised by the decreased probability of channel openings and by the accelerated decay of the synaptic response [35]. FCCMS usually present in early childhood with an infantile phenotype. FCCMS responds to 3,4-DAP in combination with pyridostigmine [35].

SCCMS SCCMS, on the contrary, is characterized by a prolonged opening time of the AchR. SCCMS are usually due to gain-of-function mutations in AchR subunit genes. In most patients, SCCMS follows an AD trait of inheritance [1]. On the contrary, most primary AchR deficiency syndromes follow an AR trait of inheritance. Mutations in any of the four AChR adult subunits can alter ion channel function of the AchR. Onset of SCCMS subtypes is usually after adolescence with initially mild phenotypes. Only rare cases present in early life and become severely disabled in the first decade [18]. In most patients there is selective, severe involvement of cervical and wrist and finger extensor muscles [35]. Electrophysiological investigations of SCCMS frequently reveal repetitive discharges (a single nerve stimulus evokes repetitive compound muscle action potentials) [1]. Intake of AchEI typically deteriorates the clinical manifestations [1]. SCCMS do not respond to edrophonium.

\section{Defects within the AchR-clustering pathway}

DOK7 The DOK7 (downstream-of-kinase) gene encodes for the protein DOK7, which is involved in signaling downstream of receptor and non-receptor phosphotyrosine kinases [70]. DOK7 activates MUSK via dimerisation [71]. Various mutations have been reported in the DOK7 gene. Particularly reported were deletions [72]. They may occur during DNA replication since there is breakpoint microhomology and an inverted repeat [72]. Concerning the frequency of DOK7-related CMS, it was the second most frequent subtype in a Brasilian cohort [10]. Clinical onset is characterised by gait disturbance due to muscle weakness after normal motor milestones [73]. Proximal limb muscles are more strongly affected than distal limb muscles (LGMD-like pattern) [73].
Congenital DOK7-related CMS may manifest as stridor due to vocal cord paralysis, occasionally requiring intubation and artificial ventilation [74]. Occasionally, patients present with ptosis but only rarely with ophthalmoparesis. Fatigability is often absent but prolonged periods of weakness may occur [75]. Feeding difficulties may require nasogastral tube feeding or even PEG implantation [74]. Muscle biopsy may show lipidosis and defective branching of terminal axons, which results in a unique terminal axon contacting en passant post-synaptic cups [76]. AchEI are usually ineffective and may even worsen clinical manifestations [73]. Ephedrine (initially $25 \mathrm{mg} / \mathrm{d}$ and increased to $75-100 \mathrm{mg} / \mathrm{d}$ ) seems to be an effective alternative [77, 78]. Salbutamol may be effective in DOK7-related CMS as well [79]. Single patients profit from albuterol, which can prevent progression of muscle weakness in LGMD-type DOK7-related CMS [80].

Musk MUSK encodes for a protein that is involved in endplate maturation, maintenance of the endplate functions, proper functioning of rapsyn, and functioning of the AchR [24]. MUSK forms a co-receptor for agrin with LRP4 and induces AchR clustering [18]. CMS due to MUSK mutations is rare and manifests as respiratory insufficiency, neonatal ptosis, proximal limb muscle weakness, and weak bulbar, facial, or ocular muscles [18]. A 30 yo Chinese male with the LGMD-type of MUSK-related CMS developed mild atrophy of the leg muscles [81]. LF-RNS was decremental. Pyridostigmin deteriorated the clinical manifestations [81]. Another male infant manifested with congenital respiratory failure requiring mechanical ventilation, axial weakness with head drop, facial weakness, proximal limb weakness, and ophthalmoparesis [82]. Salbutamol was effective but 3,4-DAP had only a mild effect, and AchEI worsened the phenotype [82]. In a female with congenital hypotonia and respiratory distress requiring mechanical ventilation for $8 \mathrm{~m}$, respiratory distress and nocturnal apnea with vocal cord paralysis recurred at age 8y [42]. 3,4-DAP was effective [42]. In two Turkish brothers MUSK mutations manifested as LGMD-type CMS [83]. MUSK-related CMS may also manifest as congenital ptosis and later in life with fatigability [84]. In another patient with MUSK-related CMS and congenital respiratory insufficiency, albuterol was moderately effective but AchEI, 3,4-DAP, and ephedrine were ineffective [85].

MYO9A The MYO9A gene encodes an unconventional myosin [86]. Mutations in the MYO9A gene causing CMS have been reported in 3 patients from 2 unrelated families [86]. Patient-1 presented as a neonate with dysphagia requiring PEG-feeding, limb muscle weakness, episodic apnoea, respiratory failure, and ptosis. SF-EMG showed an increased jitter in the orbicularis oculi 
muscle. The patient responded favourably to a combination of pyridostigmine and 3,4-DAP [86]. Patients-2 and 3 were two Kurdish siblings, both with prenatal onset with reduced fetal movements. At birth patient-2 presented with bilateral ptosis and after 2 months with generalized hypotonia and dysphagia and chewing difficulty. She had delayed motor milestones, symmetric, multivectorial nystagmus, left eye upgaze deviation, and ophthalmoplegia. Respiratory crises could be triggered by 3.4-DAP, fluoxetine, and respiratory infections. Patient-3 presented with bilateral ptosis within the first week after birth, ophthalmoplegia, nystagmus, and oculomotor apraxia, and developed generalized hypotonia, absence of head and truncal control, and difficulty with swallowing and chewing. Sitting was achieved at 12 $\mathrm{m}$, head control at $18 \mathrm{~m}$, and the ability to walk unassisted at $30 \mathrm{~m}$ of age. RNS was decremental. Both patients responded favourably to pyridostigmine. The unaffected parents were consanguineous and had previously lost four children during the first year of life, all with respiratory failure, feeding difficulties, and hypotonia [86].

AGRN The AGRN gene encodes for a proteoglycan, which is secreted by the terminal nerve into the synaptic cleft. At the post-synaptic membrane agrin binds to the LRP4 receptor to phosphorylate and activate MUSK [24]. Thus, agrin plays a critical role in the development and maintenance of the NMJ [87]. Mutations in the AGRN gene manifest phenotypically as either early-onset or late-onset CMS [24]. The infantile-onset type is characterised by weakness and wasting of the lower limbs with fatty replacement of myocytes in the posterior compartment. The late-onset type is characterised by ptosis, ophthalmoparesis, and mild facial and bulbar weakness. Rarely, mutations in the $A G R N$ gene may be associated with dropped head syndrome [87]. In a study of 5 patients from 3 families carrying $A G R N$ mutations, all presented with permanent distal muscle weakness and wasting in addition to myasthenia [88]. Both types of AGRN-related CMS respond favourably to ephedrine. Pyridostigmine and amifampridine were ineffective [24].

LRP4 The LRP4 gene encodes for a protein, which functions as a receptor for agrin [89]. LRP4 forms a complex with MUSK and mediates MUSK activation by agrin [89]. Activated MUSK together with DOK7 stimulates rapsyn to concentrate and anchor AchR at the post-synaptic membrane and interacts with other proteins implicated in the assembly and maintenance of the NMJ [90]. LRP4 is thus essential for pre- and post-synaptic specialisation of the NMJ [91]. The first mutation in the LRP4 gene causing CMS was reported in 2014 (Table 1) [90]. A newborn female presented with respiratory arrest and feeding difficulties, and required feeding and ventilator support until $6 \mathrm{~m}$ of age [90]. Motor milestones were delayed and she developed easy fatigability with temporary wheelchair-dependency [90]. At ages 9 and 14y she presented with ptosis, ophthalmoparesis, and limb weakness [90]. RNS evoked a decremental response, which improved upon application of edrophonium. AchEI worsened the clinical manifestations [90]. A second kinship harbouring LRP4 mutations was reported in 2015 [92]. The two sisters, aged 34 and $20 \mathrm{y}$, presented with delayed motor milestones, slight chewing and swallowing difficulties, and later developed limb weakness [92]. Albuterol was highly effective [92].

PREPL PREPL encodes for an ubiquitously occurring propyl-endopeptidase, with highest levels in the brain, kidneys, and muscle [93]. PREPL acts as an effector of the clathrin-associated adaptor protein-1 (AP-1) by binding to its $\mathrm{m} 1 \mathrm{~A}$ subunit to release AP-1 from target membranes [93]. Since trafficking of the vesicular acetylcholine transporter between the synaptic vesicle membrane and the cytosol depends on AP-1, absence of PREPL could explain the reduced filling of synaptic vesicles with acetylcholine [93]. Mutations in the PREPL gene cause isolated PREPL deficiency [93]. So far, only a single patient with isolated PREPL-deficiency has been reported [93]. The female presented with congenital hypotonia, feeding difficulties, ptosis, and proximal muscle weakness. She later developed a waddling gait and used a walker [93]. LF-RNS did not evoke a decrement. The patient responded favorably to edrophonium and pyridostigmine.

SCN4A SCN4A encodes for a post-synaptic sodium channel responsible for the generation of membrane action potentials. Phenotypically, mutations in this gene manifest in infancy with global hypotonia, impaired sucking, dysphagia, delayed postural and motor development and later in life with episodic, fluctuating muscle weakness like in periodic paralysis, bilateral facial palsy, ptosis, and ophthalmoparesis [94]. Episodes of periodic weakness could not be triggered by exercise, rest, potassium loading, or food, like in periodic paralysis [94]. In older patients, $S C N 4 A$-related CMS may manifest exclusively as easy fatigability [95]. In a 20 yo normokalemic female, SCN4A-related CMS manifested as sudden attacks of respiratory and bulbar paralysis since birth, lasting 3-30 min and recurring one to three times per month, delayed motor development, easy fatigability, ptosis, ophthalmoparesis, and later as persisting facial, truncal, or limb weakness [96]. Some patients present with dysmorphism, such as high-arched palate, adduction deformity of the knees or ankles, and increased lumbar lordosis. Some patients are mentally retarded 
with cerebral atrophy on MRI [96]. RNS may be normal but higher stimulus frequency may trigger a decremental response [94]. AchEI are only marginally effective [94]. Acetazolamide together with potassium was ineffective [94].

RAPSN RAPSN encodes for rapsyn, a post-synaptic membrane protein that anchors the nicotinic AchR to the motor endplate and also binds to $\beta$-dystroglycan [18]. Rapsyn is essential for clustering of the AchR at the post-synaptic membrane and required for the phosphorylation of CHRNB1 [18]. RAPSN mutations are a common cause of post-synaptic CMS [97]. The most common of the RAPSN mutation is N88G, but hetero-allelic mutations other than N88K can also occur [98, 99]. Occasionally, mutations in RAPSN become pathogenic only in case mutations in the $A K 9$ gene are simultaneously present [100]. Clinically, patients present with fluctuating ptosis, occasionally bulbar symptoms, neck muscle and mild proximal limb muscle weakness [97]. Infections can precipitate exacerbation of clinical manifestations [97]. In single patients prominent hyperlordosis can occur [101]. Usually, the response to AchEI is favourable but can be improved by adding 3,4 DAP [97]. Fluoxetine may worsen the decremental response in single patients [102]. In some patients general anesthesia may exacerbate muscle weakness [103]. The overall course is stable with intermittent worsenings [97].

PLEC1 PLEC1 encodes for plectin, which crosslinks intermediate filaments to their targets in different tissues. The gene is ubiquitously expressed but manifests mainly in the skin, gastrointestinal tract, and the NMJ. The first patient with CMS due to a PLEC1 mutation had early-onset muscular dystrophy and late-onset manifestations of a myasthenic syndrome (Table 1) [104]. RNS evoked a prominent decremental response [104]. AchEI (pyridostigmine) resulted in marked improvement of the muscular manifestations [104]. A second patient with epidermiolysis bullosa and CMS carried not only a PLEC1 mutation but also a homozygous CHRNE mutation why it was difficult to decide to which degree the PLEC1 mutation contributed to the CMS phenotype [105]. A third, Afro-American patient with epidermiolysis bullosa (EDB) developed myasthenic symptoms at age 39y [106]. RNS induced a decremental response already at age $15 y$. Histologically, NMJs showed destruction of the junctional folds and remodelling [106]. The patient died motionless at age 42y [106].

SLC25A1 SLC25A1 encodes the mitochondrial citrate carrier across the inner mitochondrial membrane and is believed to be a key player in fatty acid and sterol biosynthesis, in chromosome integrity, and in autophagy regulation [107]. Missense mutations in the SLC25A1 gene result in abnormal carrier function [107], hydroxyl-glutaric aciduria, and CMS. So far, CMS due to SLC25A1 mutations has been reported in 3 English sibs. Two of them presented with easy fatigability and permanent weakness since early infancy [107]. One had had moderate intellectual disability [107]. Another developed obsessive convulsive tendencies and had pes cavus [107]. The third patient had a more severe phenotype with poor suck, hypotonia, apneas, optic atrophy, psychomotor delay, bulbar dysfunction, epilepsy, agenesis of the corpus callosum, hearing loss, and elevated urinary organic acids [107]. RNS was normal but SF-EMG revealed an increased jitter [107]. Only one of the three patients responded favourably to 3,4-DAP [107]. Pyridostigmine was ineffective in one case.

\section{Glycosylation disorders}

CMS may not only be due to mutations in genes involved in the structure and function of the motor endplate but also in genes involved in the glycosylation of proteins, lipids, or aglykones. Particularly glycosylation of AchR is impaired in CMS due to defective glycosylation. Glycosilation is essential for proper functioning of the NMJ and takes place in the endoplasmatic reticulum (ER) [108]. Currently, mutations in five genes are known that are involved in protein glycosylation and may be associated with CMS. These genes include ALG2, ALG14, DPAGT1, GFPT1, and GMPPB [109]. Though they are ubiquitously expressed, they predominantly manifest at the NMJ. Because of the clinical and histological findings the term "limb-girdle myasthenic syndrome with tubular aggregates" was coined.

GFPT1 GFPT1 encodes for the glutamine-fructose-6-phosphate transaminase- 1 , which is a key rate-limiting enzyme that controls the flux of glucose into the hexosamine biosynthetic pathway, providing building blocks for the glycosylation of proteins and lipids [110]. GFPT1 is ubiquitously expressed but it is not readily apparent why mutations in this gene cause symptoms restricted to the NMJ [110]. Mutations in GFPT1 may lead to illegitimate binding of micro-RNAs resulting in reduced protein expression [111]. Patients manifest clinically with early-onset prominent LGMD-like weakness, easy fatigability and minimal cranio-bulbar symptoms [112, 113]. Muscle MRI may reveal T1-hyperintensities [26]. Maintenance of NMJs is dramatically impaired with loss of post-synaptic junctional folds and evidence of denervation-reinnervation processes affecting the three main NMJ components [112]. There may be mild reduction of the axon terminal size and post-synaptic fold simplification [114]. Most patients respond beneficially 
to AchEI [115]. In some patients the beneficial effect may be dramatic [116].

GMPPB GMPPB encodes the catalytic enzyme GMPPB, which converts mannose-1-phosphate and GTP to GDP-mannose. GDP-mannose serves as a sugar donor [117]. The amount of protein may be hardly reduced [118]. GMPPB mutations manifest as mild, late-onset CMS. As with other glycosylation defects, ocular and facial muscles are largely spared and limb muscles are predominantly affected [109]. Muscle weakness may be fluctuating and associated with myalgias and calf hypertrophy [118]. Creatine-kinase (CK) is frequently elevated. RNS may be decremental, SF-EMG indicates a transmission defect, and EMG may be myogenic [118]. Muscle weakness in patients carrying GMPPB mutations is non-proportionally prominent compared to only mild abnormalities on EMG or muscle MRI [109]. On the contrary, muscle biopsy shows marked dystrophic features [119]. In a review of five patients carrying GMPPB mutations, four had dystrophic features with reduced labelling for alpha-dystroglycan [119]. Muscle MRI may show fatty degeneration of paraspinal, thigh adductor, and calf muscles or edema in the soleus muscle [120] or selective involvement of the calves in single cases [118]. Onset of clinical manifestations can be $>70 \mathrm{y}$ of age [120]. Patients usually respond favourably to AchRI alone or in combination with 3,4-DAP and/or salbutamol [119].

ALG2 ALG2 encodes the $\alpha-1,3$-mannosyl-transferase that catalyses early steps in the asparagine-linked glycosylation pathway [108]. ALG2 mutations result in severely reduced expression of $A L G 2$ in muscle [108]. Phenotypically, ALG2 mutations manifest with infantile onset proximal muscle weakness, hypotonia, delayed motor milestones, and contractures [108]. Some patients may never achieve ambulation, some may develop bulbar symptoms. Severity and progression of the LGMD-like pattern muscle affection may be highly variable even within a single family [121]. RNS may be decremental. Muscle biopsy may reveal type-I-muscle fiber predominance or increased fibre-size variation [108]. Muscle biopsy may show myopathic features, ragged red fibers, and a sub-sarcolemmal accumulation of abnormally structured mitochondria [121].

ALG14 ALG14 encodes a protein that is thought to form a multi-glycosyl-transferase complex with ALG13 and DPAGT1 to catalyse the first of two committed steps of asparagine-linked protein glycosylation [108]. Clinically, a rapidly progressive, early-onset and a benign late-onset form with variable clinical presentation can be delineated [108, 122]. The first two patients reported carrying ALG14 mutations had adult-onset muscle weakness. Patients with early onset disease may present with a slightly different phenotype compared to patients with late-onset disease [122]. In a recent study of 5 early-onset patients, all presented with severe muscular hypotonia, progressive cerebral atrophy, and therapy-refractory epilepsy [122]. Three patients had congenital contractures [122]. In 2 patients, RNS was decremental. Treatment with AchEI led only to temporary improvement. All patients died during their first year of life [122].

DPAGT1 DPAGT1 encodes for an essential ER-resident enzyme catalyzing the first committed step of N-linked protein glycosylation [123]. DPAGT1 is required for efficient glycosylation of AchR subunits and for efficient export of AchRs to the cell surface [123]. Accordingly, the number of AchRs is reduced [123]. Clinically, patients present with prominent LGMD-like weakness and minimal cranio-bulbar symptoms [67]. Isolated PREPL deficiency may go along with growth hormone deficiency and cystinurea [93]. Some patients present with intellectual disability and autistic features [124]. Single patients may exhibit restricted ocular abduction and long finger flexor contractions [125]. LF-RNS evokes a typical decrement [67]. Muscle MRI may reveal T1-hyperintensities [26]. Muscle biopsy in the advanced stage shows tubular aggregates [67], hypoplastic endplates, fiber-type dysproportion, and degeneration of muscle fiber organelles resulting in autophagocytosis [124]. Typically, AchEI and 3,4-DAP are effective [67]. Neostigmine reduced the decrement but pyridostigmine had no effect [124]. 3,4DAP improved the patient's strength.

\section{Phenotypic heterogeneity and allelic variants}

There are several proteins in which the same mutations may go along with phenotypic heterogeneity (allelic variants) $[21,120]$. For example $G M P P B$ mutations may mimic LGMD or congenital muscular dystrophy in cases in which dystrophic features are more prominent than CMS features [109]. In these patients the NMJ may be morphologically normal [109]. Mutations in GMPPB not only manifest as CMS but also as dystroglycanopathy [117]. PLEC mutations may not only cause CMS but also LGMD2Q, pyloric atresia, or epidermiolysis bullosa. $\mathrm{Mu}$ tations in SLC25A7 not only cause CMS but also AD forms of distal motor neuropathy [20]. Mutations in DPAGT1 also cause congenital glycosylation-I defect and LGMD [18]. Additionally, there is intra- and inter-familial phenotypic heterogeneity despite the same genotype and a possible gender effect [14]. It is also important to mention that primary myopathies may go along with secondary transmission disease, which does not represent CMS, such as in patients with congenital myopathy due to TPM2 mutations [126], or patients 
carrying mutations in KLHL40, BIN1, DNM2, MTM1, TPM3, or RYR1. Importantly, secondary transmission disease frequently responds beneficially to AchEI.

\section{Diagnosis}

Diagnosing CMS relies on a thorough work-up by means of the history, clinical exam, blood tests, electrophysiological investigations, lung function tests, polysomnography, the tensilon test, eventually muscle biopsy, and the confirmation of a heterocygote or biallelic pathogenic variant in one of the 32 CMS genes. A CMS should be generally suspected if 1 . there is easy fatigability or permanent weakness, most frequently in the ocular, facial, bulbar, axial, respiratory, or limb muscles with onset from birth to childhood; 2 . the family history is positive for clinical manifestations of CMS; 3. history and clinical exam suggest myasthenia gravis but where AchR-, MUSK-, and LRP4-antibody tests are negative; 4. LF-RNS evokes a decrement of $>10 \%$ or if SF-EMG shows increased jitter or blockings; 5 . clinical manifestations respond to AchEI; 6. there is a lack of improvement upon immunosuppressive therapy; 7. the family history suggests an $\mathrm{AD} / \mathrm{AR}$ transmitted disease; 8 . there is absence of a major pathology on muscle biopsy; and if 9. a specific syndrome (e.g. Escobar syndrome, Pierson syndrome (eye disease and nephropathy)) is present [24]. Mixing phenotype and age at onset, three phenotypes can be differentiated, which are the infantile-onset type, childhood-onset type, and the LGMD-type [6].

\section{History}

In case the history can be taken, patients may report easy fatigability, fluctuating or permanent weakness of ocular, bulbar, facial, axial, or limb muscles, double vision, ptosis, dysarthria, dysphagia, hypoacusis, head drop, or respiratory insufficiency. Patients may also recognise dysmorphism, they may report neuropathic pain, seizures, pterygia, contractures, hyperlaxity of joints, abnormal speech, cognitive impairment, respiratory insufficiency, or skeletal deformities.

\section{Clinical exam}

The neurological exam may be normal or abnormal.

Muscular features Muscular abnormalities include ptosis, ophthalmoparesis, facial weakness, bulbar weakness (dysarthria, dysphagia), axial weakness (head drop, camptocormia), dyspnea, limb weakness, hypotonia, or reduced tendon reflexes. Rarely, patients may present with muscle wasting, particularly of limb muscles [81]. Atrophy of the skeletal muscles is particularly reported in MUSK-related CMS [81].
Table 3 Typical clinical manifestations of CMS subtypes

\begin{tabular}{ll}
\hline Phenotypic feature & CMS subtypes \\
\hline Myopathic & \\
LGMD-type & COLQ, DOK7, MUSK, GFPT1, \\
& ALG2, ALG14, DPAGT1 \\
Respiratory insufficiency & SLC18A3, SYB1, COLQ, LAMB2, \\
& CHRNB1, CHRND, CHRNE, CHRNG, \\
& MUSK, NYO9A, LRP4, COL13A1, \\
& SCN4A, RAPS \\
Episodic apnea & CHAT, MUSK, SLC5A7, SLC25A1, \\
& RAPSN, COLQ \\
Head drop & AGRN \\
Myopathic EMG & CHRNB1, ALG2, PLEC1, GMPPB \\
Double response & CHRNE, COLQ, SCCMS, ACHE-deficiency, \\
& CHRNA1, CHRNB1, CHRND
\end{tabular}

Non-myopathic

Cognitive dysfunction

SLC25A7, DPAGT1, SNAP25, COL13A1, MYO9A, CHRNB1, CHRND

Facial tics

LAMA5

Cerebral atrophy

SCN4A, ALG14

Agenesis of corpus callosu

Epilepsy

SLC25A1

Facial dysmorphism

Myopia

ALG14, SLC25A1, MUNC13-1

Hypoacusis

SYB1, RAPSN, SCN4A, COLQ

LAMA5

Vocal cord paralysis

SLC25A1, SYT2

Neuropathy

COLQ, DOK7

Arthrogryposis multiplex

SYT2, SLC25A7

Contractures

SLC5A7, CHRNG

SNAP25, VAMP1, CHRNA1, ALG2, ALG14, RAPSN, CHRND, CHRNG, CHAT

Scoliosis

COLQ, CHRNE, VAMP1

Hyperlordosis,

hyperkyphosis

Adduction deformity of

SCNA4, RAPSN, SYB1

SCN4A

knees

Cubitus valgus

PLEC1

Foot deformity

SYT2, RAPSN, CHRNG, SLC25A1, COLQ

Hyperlaxity of joints

SYT2, VAMP1, COL13A1

Cutaneous blisters

PLEC1

Pterygia

CHRNG

Systolic dysfunction

SLC18A3

Pierson syndrome

LAMB2

Cerebellar ataxia

SNAP25

Laryngospasm

SCN4A

Deterioration in cold water

SLC18A3

Hip dysplasia

SYT2

Cryptorchism

CHRNG

Arachnodactylia

CHRNG

Microcephaly

MUNC13-1 


\section{Non-muscle signs}

Facial dysmorphism There are a number of dysmorphic features that occur in specific CMS subtypes [54]. These include long face (SYB1) [7], hypertelorism (SYB1) [7], narrow jaw (RAPSN), saddle nose (SYB1) [7], and high-arched palate $(S C N 4 A)$ [96]. In a Saudi female carrying a COLQ mutation, microcephaly was reported (Table 3) [41]. Microcephaly was also reported in MUNC13-1-related CMS.

Skeletal abnormalities Hyperlordosis or hyperkyphosis were reported in patients carrying SCN4A [97], RAPSN [101], or SYB1 [7] mutations. Scoliosis may occur in CHRNE-related CMS [27] but also in COLQ-related CMS [43]. Foot deformities include pes cavus (hollow foot), pes planus, or hammertoes (SYT2-related CMS [127], SLC25A1). Club feet have been found in RAPSN-related CMS [54], and COLQ-related CMS [41]. In $S C N 4 A$-related CMS adduction deformity of the knees and ankles were reported [96]. Cubitus valgus was reported in PLEC1-associated CMS [106]. Hyperlaxity of joints and hip dysplasia may occur in SYT2-related CMS [32]. Joint laxity and kyphoscoliosis were reported in association with VAMP1 [31] and COL13A1 variants.

Cognitive impairment/neurodevelopmental delay Cognitive dysfunction is only rarely a manifestation of a CMS phenotype. Mild to severe cognitive impairment has been reported in patients carrying mutations in the SLC5A7 gene, DPAGT1 gene [124], SNAP25 gene [30], COL13A1 gene [52], MYO9A gene [86], MUNC13-1 gene, and in SCN4A-related CMS [20,96]. In a study of 6 families, half of the probands carrying a SLC25A7 mutation had mild cognitive impairment [20]. Recently, mutations in the SLC18A3 gene have been shown to manifest as neurodevelopmental delay with cerebral atrophy [21]. Mutations in this gene may be also associated with infantile lethality [21]. Mild cerebral atrophy was reported in SCN4A-related CMS [96] and in ALG14-related CMS [123].

Neuropathy Mutations in CMS genes, such as in SYT2, not only manifest in the skeletal muscle but also in the peripheral nerves as polyneuropathy [128]. Also SLC5A7 mutations may manifest with distal neuropathy [21].

Epilepsy There are a number of patients diagnosed with CMS who also had epilepsy. Epilepsy was reported in patients with CMS due to SLC25A1 mutations [107], due to MUNC13-1 mutations, or due to ALG14 mutations [122].

Others Cutaneous blisters of the dermis or the mucosa may be found in PLEC1-related CMS [106]. Agenesis of the corpus callosum and hearing loss have been reported in MUNC13-1-related [36] and SLC25A1-related CMS [107]. Two patients with COLQ-related CMS manifested with vocal cord paralysis [42]. Single patients with AchR-related CMS may develop pterygia. In SLC18A3-related CMS, systolic dysfunction was reported [29]. In a female with a $L A M A 5$-variant, myopia and facial tics were described [51].

\section{Blood tests}

CK may be normal [81] or mildly elevated (maximally 10 times the upper limit) $[1,6]$, with the exception of GMPPB-related CMS. Antibodies against AchR, MUSK, or RLP4 are usually absent, being one of the diagnostic criteria for CMS [129].

\section{Electrophysiologic evaluation}

The most important electrophysiological investigation to support the CMS diagnosis are LF-RNS and HF-RNS. LF-RNS usually shows a decrement and only rarely an increment. If RNS is normal in two limb muscles, RNS of the facial muscles should be tried. HF-RNS usually shows an increment and only rarely a decrement [94, 130]. In patients carrying $S C N 4 A$ variants, LF-RNS may be normal but may show a decremental response at higher stimulus rates [94]. Pre-synaptic CMS may not only be detected upon a profound decrement to LF-RNS but also by a prolonged period of post-activation exhaustion (decreased neuromuscular transmission on RNS after previous intense muscle contraction) [29]. In patients with RAPSN-related CMS, HF-RNS was followed by a decrement instead of the expected increment [130]. If RNS is normal, muscle contractions or exercise should be performed prior to the test. Instead of voluntary muscle contractions, $10 \mathrm{~Hz}$ stimulation during 5-10 min prior to LF-RNS may help to unmask an abnormal decrement or increment. In patients carrying SYT1 mutations, CMAP amplitudes may be initially low but may markedly increase after forced exercise, like in Lambert-Eaton myasthenic syndrome [127]. If RNS is still normal, but still suspicion of a CMS, single fiber EMG is indicated, which may show increased jitter or increased number of blockings despite normal RNS [107]. Another test to unmask a NMJ defect is application of a single stimulus, which may be followed by a spontaneous second one (double response). The double response phenomenon can be typically observed in COLQ-related CMS and in SCCMS. In some patients needle-EMG may be myopathic [10]. Contrary to patients with periodic paralysis, myotonia may be absent on EMG in SCN4A-related CMS [94]. 


\section{Lung function, polysomnography}

Essential investigations to assess respiratory functions and to identify patients with nocturnal hypoventilation include lung function tests, arterial blood gas analysis, and polysomnography. Polysomnography is important to detect sleep disorders due to nocturnal apnoe/hypopnea recently reported in COLQ- and RAPSN-related CMS [131]. Symptoms indicative of nocturnal hypoventilation include daytime headache, restless sleep, impaired concentration, snoring, recurrent respiratory infections, or weight loss [6]. Applicability of lung function tests is restricted to cooperative patients. Non-cooperating patients may be investigated only by blood gas analyses and polysomnography.

\section{Tensilon test}

Though testing with edrophonium is frequently proposed, there are hardly reports about the details in patients with CMS. Generally, the test should be carried out only on an intermediate care unit (ICU) [6]. Initially, $2 \mathrm{mg}$ should be applied, followed by another $2-5 \mathrm{mg}$ in patients $>30 \mathrm{~kg}$ [6]. The dosage may be less in neonates and infants. The strongest effect will be achieved after 30s. Before the test, it is important to define an endpoint, such as ptosis, ophthalmoparesis, or weakness of limb muscles. Alternatively to edrophonium, pyridostigmine can be applied orally. Some patients with CHRNE mutations may show a striking response to the ice pack test [64].

\section{Muscle biopsy}

Muscle biopsy is normal in the majority of the cases. However, in glycosylation disorders due to mutations in the GFPT1 gene tubular aggregates with synaptopathy and dramatic loss of post-synaptic functional folds and evidence of denervations/reinnervation processes affecting the three main NMJ components can be found [112]. In patients carrying MUSK mutations, increased fiber-size variability has been reported [81]. Patients with COLQ- or GMPPB-related CMS may show dystrophic features on muscle biopsy [45, 121]. Patients with COLQ- and ALG2-related CMS may show type-I-fiber predominance $[45,108]$.

\section{Genetic testing}

The most important investigations for diagnosing CMS are genetic tests. Different approaches for genetic testing can be applied, including single gene testing, multiple gene panel testing, or comprehensive genetic testing (WES, whole genome sequencing (WGS)) [6]. Single gene testing is indicated if a single gene accounts for a large proportion of the phenotype or if the phenotype and ancestry suggest a mutation in a particular gene as most likely. Sequencing of the gene of interest is carried out first, followed by gene-targeted deletion / duplication analysis [6]. Particular phenotypic features (apnea, non-response to AchEI, double response, increment on RNS, dysmorphism, foot deformities, neuropathy, epilepsy, contractures, $\mathrm{AD} / \mathrm{AR}$ trait, or the ethnic origin (Maghreb, Roma, Spain/Portugal, Central/ Western Europe) may guide the clinician to suspect a particular CMS subtype. For example, AD transmission is indicative of SYT1-, SLC5A7-, SNAP25-related, and SCCMS subtypes, usually present after adolescence with mild phenotypes. Only rare cases present in early life and become severely disabled in the first decade [18]. On the contrary, FCCMS usually present in early childhood with an infantile phenotype.

Due to the phenotypic heterogeneity, however, multi-gene panels are emerging as first-line diagnostic tool. If serial single gene testing or multi-gene panels fail to establish the diagnosis, WES should be considered [6].

\section{Differential diagnoses}

Differential diagnoses that have to be excluded before diagnosing CMS in adults include myasthenia gravis, motor neuron disease, including Kennedy disease, limb girdle muscular dystrophy, facio-scapulo-humeral muscular dystrophy, mitochondrial disorders, and hereditary neuropathies (Table 4). Myasthenia gravis usually has its onset in adulthood, however, when patients with myasthenia are young and sero-negative, differentiation from CMS can be challenging. Differential diagnoses that have to be excluded before diagnosing CMS in infants or

Table 4 Differential diagnoses of CMS

\begin{tabular}{|c|c|c|}
\hline Differential diagnosis & Early onset & Adult onset \\
\hline FADS & yes & no \\
\hline Periodic paralysis (SCNA4) & yes & yes \\
\hline CDG & yes & no \\
\hline Spinal muscular atrophy & yes & yes \\
\hline Mitochondrial disorders & yes & yes \\
\hline Myasthenia gravis & no & yes \\
\hline Transient neonatal myasthenia & yes & no \\
\hline Congenital muscular dystrophy & yes & no \\
\hline Congenital myopathies & yes & no \\
\hline Congenital myotonic dystrophy & yes & no \\
\hline Brain stem abnormalities & yes & yes \\
\hline Moebius syndrome & yes & no \\
\hline (Infantile) botulism & yes & yes \\
\hline Kennedy disease & no & yes \\
\hline LGMD & yes & yes \\
\hline FSH-MD & yes & yes \\
\hline Hereditary neuropathies & yes & yes \\
\hline
\end{tabular}

FADS Fetal akinesia deformation sequence, CDG congenital disease of glycosylation, $L G M D$ limb girdle muscular dystrophy, FSH-MD facio-scapulohumeral muscular dystrophy 
children include transient neonatal myasthenia gravis, spinal muscular atrophy, congenital muscular dystrophy, congenital myotonic dystrophy-1, early-onset mitochondrial disorder, congenital myopathy, brainstem lesions, Moebius syndrome, and botulism (Table 4). Clinical phenotypes of CMS share significant overlap in their clinical presentations with mitochondrial disorders, leading to challenges in establishing the correct diagnosis [45].

\section{Therapy}

Therapy of CMS is not standardised due to the low number of patients and thus the lack of sufficiently powered treatment studies. Additionally, the genotypic and phenotypic heterogeneity makes it difficult to recruit homogenous groups required for treatment studies. Due to the rarity of CMS, therapy trials will meet the requirements for an appropriately designed treatment study only when applying an international, multicentre design. Generally, treatment may be classified as symptomatic or causal, invasive or non-invasive, or as established or experimental. Since no causal treatment for CMS is available, only symptomatic measures can be offered to these patients. Among the non-invasive symptomatic measures, drug treatment and non-drug treatment can be differentiated. Disadvantage of most reports is that dosages of agents applied, type of combinations, and duration of drug therapy are frequently not or insufficiently reported. There are also hardly reports available about side effects of the various agents applied.

\section{Non-invasive symptomatic treatment}

Drugs There are several drugs available, which are applied to CMS patients but since some of them may exhibit severe side effects, these drugs need to be applied with caution until there is clear evidence that a particular patient profits from such compounds. Only in case of an emergency in a suspected CMS, drugs can be tried without previous genetic confirmation of the diagnosis.

AchE-inhibitors AchEI are the drugs most frequently given to CMS patients (Table 5) but may not be effective in each of them (Table 5) [42]. AchEI may even deteriorate clinical manifestations in certain subtypes of CMS, such as in COLQ-, LAMB2-, DOK7-, MUSK-, or LRP4-related CMS. In case of an infection, prophylactic application of AchEI may be recommended. Prophylactic AchEI together with antibiotics may prevent the occurrence of episodic apnea and respiratory insufficiency.

4-Diaminopyridine The most frequently applied alternative drug to AchEI or the one most frequently given in combination with AchEI is 3,4-DAP. 3,4-DAP increases the amount of acetylcholine released to the
Table 5 Effectiveness of drug treatment in the 32 CMS subtypes

\begin{tabular}{|c|c|c|c|c|c|}
\hline CMS subtype & AchEI\& & 3,4-DAP & SALB & ALB & Ephed \\
\hline \multicolumn{6}{|l|}{ Pre-synaptic } \\
\hline SLC5A7 & e & $\mathrm{nr}$ & e & $\mathrm{nr}$ & $\mathrm{nr}$ \\
\hline CHAT & pe & $\mathrm{nr}$ & $\mathrm{nr}$ & $\mathrm{nr}$ & $\mathrm{nr}$ \\
\hline SLC18A3 & pe & $\mathrm{nr}$ & $\mathrm{nr}$ & $\mathrm{nr}$ & $\mathrm{nr}$ \\
\hline SNAP25 & ie & e & $\mathrm{nr}$ & $\mathrm{nr}$ & $\mathrm{nr}$ \\
\hline VAMP1 & e & $\mathrm{nr}$ & $\mathrm{nr}$ & $\mathrm{nr}$ & $\mathrm{nr}$ \\
\hline SYB1 & pe & $\mathrm{nr}$ & $\mathrm{nr}$ & $\mathrm{nr}$ & $\mathrm{nr}$ \\
\hline SYT2 & pe & e & $\mathrm{nr}$ & $\mathrm{nr}$ & $\mathrm{nr}$ \\
\hline MUNC13-1 & pe & pe & $\mathrm{nr}$ & $\mathrm{nr}$ & $\mathrm{nr}$ \\
\hline \multicolumn{6}{|l|}{ Synaptic } \\
\hline COLQ & ie & pe & e & $\mathrm{nr}$ & e \\
\hline LAMB2 & ie & pe & e & $\mathrm{nr}$ & e \\
\hline LAMA5 & e & e & $\mathrm{nr}$ & $\mathrm{nr}$ & $\mathrm{nr}$ \\
\hline COL13A1 & ie & e & e & $\mathrm{nr}$ & $\mathrm{nr}$ \\
\hline
\end{tabular}

Post-synaptic

$\begin{array}{lllllll}\text { CHRNA1 } & \text { e/pe } & \mathrm{nr} & \mathrm{nr} & \mathrm{nr} & \mathrm{nr} & \mathrm{nr} \\ \text { CHRNB1 } & \text { ie } & \mathrm{nr} & \mathrm{nr} & \mathrm{nr} & \mathrm{pe} & \mathrm{e} \\ \text { CHRND } & \text { pe } & \text { e } & \mathrm{nr} & \mathrm{nr} & \mathrm{nr} & \mathrm{nr} \\ \text { CHRNE } & \text { e/ie } & \text { e } & \mathrm{e} & \mathrm{e} & \mathrm{nr} & \mathrm{e} \\ \text { CHRNG } & \mathrm{nr} & \mathrm{nr} & \mathrm{nr} & \mathrm{nr} & \mathrm{nr} & \mathrm{nr} \\ \text { FCCMS } & \text { e } & \mathrm{e}^{\mathrm{a}} & \mathrm{nr} & \mathrm{nr} & \mathrm{nr} & \mathrm{nr} \\ \text { SCCMS } & \mathrm{nr} & \mathrm{nr} & \mathrm{nr} & \mathrm{nr} & \mathrm{nr} & \mathrm{e} \\ \text { DOK7 } & \text { ie } & \mathrm{nr} & \mathrm{e} & \mathrm{e} & \mathrm{e} & \mathrm{nr} \\ \text { MUSK } & \text { ie } & \mathrm{ie} / \mathrm{e} & \mathrm{e} & \mathrm{pe} & \mathrm{ie} & \mathrm{nr} \\ \text { MYO9A } & \mathrm{e} & \mathrm{e} & \mathrm{nr} & \mathrm{nr} & \mathrm{nr} & \mathrm{nr} \\ \text { AGRN } & \text { ie } & \mathrm{nr} & \mathrm{nr} & \mathrm{nr} & \mathrm{e} & \mathrm{nr} \\ \text { LRP4 } & \text { ie } & \mathrm{nr} & \mathrm{nr} & \mathrm{e} & \mathrm{nr} & \mathrm{nr} \\ \text { PREPL } & \text { e } & \mathrm{nr} & \mathrm{nr} & \mathrm{nr} & \mathrm{nr} & \mathrm{nr} \\ \text { SCN4A } & \text { pe } & \mathrm{nr} & \mathrm{nr} & \mathrm{nr} & \mathrm{nr} & \mathrm{nr} \\ \text { RAPSN } & \text { e } & \mathrm{e} & \mathrm{nr} & \mathrm{nr} & \mathrm{e} & \mathrm{nr} \\ \text { PLEC1 } & \text { e } & \mathrm{nr} & \mathrm{nr} & \mathrm{nr} & \mathrm{nr} & \mathrm{nr} \\ \text { SLC25A1 } & \text { ie } & \mathrm{e} & \mathrm{nr} & \mathrm{nr} & \mathrm{nr} & \mathrm{nr}\end{array}$

Glycosilation defect

$\begin{array}{lllllll}\text { GFPT1 } & \text { e } & \mathrm{nr} & \mathrm{nr} & \mathrm{nr} & \mathrm{nr} & \mathrm{nr} \\ \text { GMPPB } & \text { e } & \mathrm{e}^{\mathrm{a}} & \mathrm{e} & \mathrm{nr} & \mathrm{nr} & \mathrm{nr} \\ \text { ALG2 } & \mathrm{e} & \mathrm{nr} & \mathrm{nr} & \mathrm{nr} & \mathrm{nr} & \mathrm{nr} \\ \text { ALG14 } & \mathrm{pe} & \mathrm{nr} & \mathrm{nr} & \mathrm{nr} & \mathrm{nr} & \mathrm{nr} \\ \text { DPAGT1 } & \mathrm{e} & \mathrm{e} & \mathrm{nr} & \mathrm{nr} & \mathrm{nr} & \mathrm{nr}\end{array}$

SALB: salbutamol, ALB: albuterole, Ephed: ephedrine, pe: partially effective, $\mathrm{nr}$ : not reported, e: effective, ie: ineffective, ${ }^{a}$ : in combination with $A c h E l,{ }^{b}:$ in combination with 3,4-DAP, \&: in COLQ-, LAMB2-, DOK7-, MUSK-, and LRP4related CMS AchEI may deteriorate the clinical manifestations 
synaptic cleft. Additionally, it prolongs the presynaptic action potential. 3,4-DAP is not only effective in pre-synaptic but also in post-synaptic CMS [129]. 3,4-DAP may have only a mild beneficial effect in COLQ-related or LAMB2-related CMS (Table 5) [42]. 3,4-DAP may be ineffective in CHRNE- or MUSK-related CMS (Table 5). 3,4-DAP may be detrimental in FCCMS due to AR loss-of-function mutations and should be avoided in these conditions [12].

Salbutamol Salbutamol is a $\beta 2$-mimetic, which has been reported beneficial in SLC5A7-, COLQ-, CHRNE-, DOK7-, MUSK-, COL13A1-, and GMPPB-related CMS (Table 5) [14, 48].

Albuterol Albuterol is a bronchodilator and an alternative to ephedrine and has a beneficial role in CHRNEand MUSK-related CMS (Table 5).

Ephedrine Ephedrine is an alkaloid from the group of phenyl-ethyl-amines, originating from the plant ephedra. It is used in medicine as a sympathomimetic agent, for asthma, as a decongestant, and in ophthalmology as a supplement of atropine. Ephedrine is usually well tolerated. It has been reported effective in COLQ-, LAMB2-, $D O K 7-$, and $A G R N$-related CMS (Table 5). In a patient with $C O L Q$-related CMS manifesting as vocal cord paralysis, hypotonia, ptosis, ophthalmoparesis, and facial diplegia, ephedrine was highly effective [42]. Ephedrine was ineffective in MUSK-related CMS [85].

Fluoxetine Reports about the effect of fluoxetine in CMS are conflicting. While a beneficial effect has been reported in CHRNB1 and CHRNE-related CMS (Table 5), fluoxetine worsened the clinical manifestations in MYO9A- and RAPSN-related CMS. Fluoxetine has been reported beneficial for muscle weakness in patients with SCCMS [132].

Others/experimental Only single reports are available about the effect of acetazolamide, quinidine, and atracurium. Recently, zonisamide has been shown beneficial in experimental CMS, being attributed to its nerve-sprouting activity [133].

Non-drug treatment Non-invasive, non-drug treatment relies on physiotherapy, speech therapy, and occupational therapy. To warrant mobility, orthoses, walkers, or wheel chairs may be used. Generally, patients with CMS should avoid strenuous exercise or infections, which may exacerbate symptoms of a transmission disease. NIPPV either during the night or the entire day may support insufficient self-breathing. In animals, antisense oligonucleotides (AONs) have been shown to be beneficial in CHRNA1-related CMS [53].

\section{Invasive measures}

In case of dysphagia, failure-to-thrive, or a nutritional disturbance, implantation of a PEG may be necessary. In case of respiratory insufficiency without the possibility of a NIPPV, intubation and mechanical ventilation may be indicated. Severe, symptomatic scoliosis may require surgical spinal correction [49]. Foot deformities may require surgical corrections.

\section{Pregnancy and CMS}

Pregnancy has been reported to exacerbate clinical manifestations of CMS [134]. In a study of 17 pregnancies of females from 8 families with a CMS it turned out that pregnancy deteriorated clinical manifestations of CMS [135]. In most cases, affected females recovered to the status quo ante within six months postnatally [135]. The outcome of neonates born to females with CMS is fair except in females with SCCMS [135]. To warrant a good outcome from pregnancy, close neurological surveillance is necessary.

\section{Prognosis and outcome}

Prospective outcome studies are not available but in several observational studies, case studies, and case reports, the outcome has been mentioned. In a study of 79 CMS patients, those carrying a DOK7 mutation had the worst outcome [134]. Among the 8 patients being wheel-chair-bound and ventilated, 6 carried a $D O K 7$ variant [134]. Since the clinical presentation is highly variable, also the outcome and prognosis may vary considerably between the various CMS types. The outcome is further influenced by acute deteriorations due to infections, fever, or psychosocial stress.

\section{Conclusions}

Currently, 8 pre-synaptic, 4 synaptic, 15 post-synaptic, and 5 glycosilation defects are known to cause CMS. The most frequently reported CMS subtypes are COLQ-, CHRNE-, RAPSN-, DOK7-, and CHAT-related CMS (Table 1). Though CMS are congenital in the majority of the cases, it becomes increasingly evident that in some subtypes the onset may be in early or even late adulthood. However, severity of the disease is usually more pronounced in early-onset subtypes. Due to their intra- and inter-familial phenotypic heterogeneity, CMSs can be easily mixed up with other neuromuscular disorders, particularly LGMDs and mitochondrial disorders. A number of promising proposals have been launched for the treatment of certain CMS subtypes during recent years. They should be further evaluated to find out if they are also effective in other CMS subtypes. These measures include the application of a gene therapy with AONs and the application of zonisamide, which may trigger axonal sprouting. Whenever patients with 
myasthenic symptoms do not present with AchR- or MUSK-antibodies, do not respond to immunosuppressive treatment, have a positive family history for their phenotype, and show impaired neuromuscular transmission upon RNS or SF-EMG, a CMS should be considered.

\section{Abbreviations}

AchEl: Acetylcholine-esterase inhibitors; AchR: Acetylcholine-receptor; AD: Autosomal dominant; AON: Antisense-oligonucleotide; AR: Autosomal recessive; CMAP: Compound muscle action potential; CMD: Congenital muscular dystrophy; CMS: Congenital myasthenic syndrome; DAP: Diaminopyridine; DNA: Desoxiribonucleic acid; EDB: Epidermiolysis bullosa; EMG: Electromyography; ER: Endoplasmatic reticulum; FADS: Fetal akinesia deformation sequence; ICU: Intermediate care unit; LF-RNS: Lowfrequency RNS; LGMD: Limb girdle muscular dystrophy; MRI: Magnetic resonance imaging; NIPPV: Non-invasive positive pressure ventilation; NMJ: Neuromuscular junction; PEG: Percutaneous entero-gastrostomy; RNS: Repetitive nerve stimulation; SF-EMG: Single-fiber electromyography; VAchT: Vesicular acetylcholine transporter; WES: Whole exome sequencing; WGS: Whole genome sequencing

\section{Acknowledgements}

not applicable.

\section{Funding}

none received.

\section{Availability of data and materials}

please contact author for data requests.

\section{Authors' contributions}

JF was responsible for everything. The author read and approved the final manuscript.

\section{Ethics approval and consent to participate}

not applicable.

\section{Consent for publication}

not applicable.

\section{Competing interests}

the author declares that he has no competing interests.

\section{Publisher's Note}

Springer Nature remains neutral with regard to jurisdictional claims in published maps and institutional affiliations.

\section{Received: 8 March 2018 Accepted: 7 February 2019}

Published online: 26 February 2019

\section{References}

1. Engel AG, Shen XM, Selcen D, Sine SM. Congenital myasthenic syndromes: pathogenesis, diagnosis, and treatment. Lancet Neurol. 2015;14:420-34.

2. Zhang Y, Dai Y, Han JN, Chen ZH, Ling L, Pu CQ, Cui LY, Huang XS. A novel AGRN mutation leads to congenital Myasthenic syndrome only affecting limb-girdle muscle. Chin Med J. 2017;130:2279-82.

3. Bestue-Cardiel M, Natera-de BD. Current status of congenital myasthenic syndromes. Rev Neurol. 2017;65:161-76.

4. Gomez CM, Gammack JT. A leucine-to-phenylalanine substitution in the acetylcholine receptor ion channel in a family with the slow-channel syndrome. Neurology. 1995;45:982-5.

5. Ohno K, Tsujino A, Brengman JM, Harper CM, Bajzer Z, Udd B, Beyring R, Robb S, Kirkham FJ, Engel AG. Choline acetyltransferase mutations cause myasthenic syndrome associated with episodic apnea in humans. Proc Natl Acad Sci U S A. 2001;98:2017-22.

6. Abicht A, Müller J S, Lochmüller H. Congenital Myasthenic syndromes. 2003 may 9 [updated $2016 \mathrm{Jul}$ 14]. In: Adam MP, Ardinger HH, Pagon RA, Wallace SE, Bean LJH, Mefford HC, Stephens K, Amemiya A, Ledbetter N, editors.
GeneReviews ${ }^{\ominus}$ [internet]. Seattle (WA): University of Washington, Seattle; 1993-2017. Available from http://www.ncbi.nlm.nih.gov/books/NBK1168/.

7. Shen XM, Scola RH, Lorenzoni PJ, Kay CS, Werneck LC, Brengman J, Selcen $D$, Engel AG. Novel synaptobrevin-1 mutation causes fatal congenital myasthenic syndrome. Ann Clin Transl Neurol. 2017;4:130-8.

8. Rodríguez Cruz PM, Palace J, Beeson D. Inherited disorders of the neuromuscular junction: an update. J Neurol. 2014;261:2234-43.

9. Parr JR, Andrew MJ, Finnis M, Beeson D, Vincent A, Jayawant S. How common is childhood myasthenia? The UK incidence and prevalence of autoimmune and congenital myasthenia. Arch Dis Child. 2014;99:539-42.

10. Mihaylova V, Scola RH, Gervini B, Lorenzoni PJ, Kay CK, Werneck LC, Stucka R, Guergueltcheva V, von der Hagen M, Huebner A, Abicht A, Müller JS, Lochmüller $\mathrm{H}$. Molecular characterisation of congenital myasthenic syndromes in southern Brazil. J Neurol Neurosurg Psychiatry. 2010;81:973-7.

11. Morar B, Gresham D, Angelicheva D, Tournev I, Gooding R, Guergueltcheva V, Schmidt C, Abicht A, Lochmuller H, Tordai A, Kalmar L, Nagy M, Karcagi V, Jeanpierre M, Herczegfalvi A, Beeson D, Venkataraman V, Warwick Carter K, Reeve J, de Pablo R, Kucinskas V, Kalaydjieva L. Mutation history of the Roma/gypsies. Am J Hum Genet. 2004;75:596-609.

12. Beeson D, Hantaï D, Lochmüller H, Engel AG. 126th international workshop: congenital myasthenic syndromes, 24-26 September 2004, Naarden, the Netherlands. Neuromuscul Disord. 2005;15:498-512.

13. Chang T, Cossins J, Beeson D. A rare C.183_187dupCTCAC mutation of the acetylcholine receptor CHRNE gene in a South Asian female with congenital myasthenic syndrome: a case report. BMC Neurol. 2016;16: 195.

14. Ardissone A, Moroni I, Bernasconi P, Brugnoni R. Congenital myasthenic syndrome: phenotypic variability in patients harbouring p.T159P mutation in CHRNE gene. Acta Myol. 2017;36:28-32.

15. Aharoni S, Sadeh M, Shapira Y, Edvardson S, Daana M, Dor-Wollman T, Mimouni-Bloch A, Halevy A, Cohen R, Sagie L, Argov Z, Rabie M, Spiegel R, Chervinsky I, Orenstein N, Engel AG, Nevo Y. Congenital myasthenic syndrome in Israel: genetic and clinical characterization. Neuromuscul Disord. 2017;27:136-40.

16. Harper CM. Congenital myasthenic syndromes. Semin Neurol. 2004;24:111-23.

17. Abath Neto O, Heise CO, Moreno CA, Estephan EP, Mesrob L, Lechner D, Boland A, Deleuze JF, Oliveira AS, Reed UC, Biancalana V, Laporte J, Zanoteli E. Nonlethal CHRNA1-related congenital Myasthenic syndrome with a homozygous null mutation. Can J Neurol Sci. 2017;44:125-7.

18. Ohno K, Ohkawara B, Mikako I. Recent advances in congenital myasthenic syndromes. Clin Experiment Neuroimmunol. 2016;7:246-59.

19. Aran A, Segel R, Kaneshige K, Gulsuner S, Renbaum P, Oliphant S, Meirson T, Weinberg-Shukron A, Hershkovitz Y, Zeligson S, Lee MK, Samson AO, Parsons SM, King MC, Levy-Lahad E, Walsh T. Vesicular acetylcholine transporter defect underlies devastating congenital myasthenia syndrome. Neurology. 2017:88:1021-8.

20. Bauché S, O'Regan S, Azuma Y, Laffargue F, Mcmacken G, Sternberg D, Brochier G, Buon C, Bouzidi N, Topf A, Lacène E, Remerand G, Beaufrere AM, Pebrel-Richard C, Thevenon J, El Chehadeh-Djebbar S, Faivre L, Duffourd Y, Ricci F, Mongini T, Fiorillo C, Astrea G, Burloiu CM, Butoianu N, Sandu C, Servais L, Bonne G, Nelson I, Desguerre I, Nougues MC, Bœuf B, Romero N, Laporte J, Boland A, Lechner D, Deleuze JF, Fontaine B, Strochlic L, Lochmuller H, Eymard B, Mayer M, Nicole S. Impaired Presynaptic HighAffinity Choline Transporter Causes a Congenital Myasthenic Syndrome with Episodic Apnea. Am J Hum Genet. 2016;99:753-61.

21. Wang H, Salter CG, Refai O, Hardy H, Barwick KES, Akpulat U, Kvarnung M, Chioza BA, Harlalka G, Taylan F, Sejersen T, Wright J, Zimmerman HH, Karakaya M, Stüve B, Weis J, Schara U, Russell MA, Abdul-Rahman OA, Chilton J, Blakely RD, Baple EL, Cirak S, Crosby AH. Choline transporter mutations in severe congenital myasthenic syndrome disrupt transporter localization. Brain. 2017;140:2838-50.

22. Maselli RA, Chen D, Mo D, Bowe C, Fenton G, Wollmann RL. Choline acetyltransferase mutations in myasthenic syndrome due to deficient acetylcholine resynthesis. Muscle Nerve. 2003;27:180-7.

23. Barisic N, Müller JS, Paucic-Kirincic E, Gazdik M, Lah-Tomulic K, Pertl A, Sertic J, Zurak N, Lochmüller H, Abicht A. Clinical variability of CMS-EA (congenital myasthenic syndrome with episodic apnea) due to identical CHAT mutations in two infants. Eur J Paediatr Neurol. 2005;9:7-12.

24. Souza PV, Batistella GN, Lino VC, Pinto WB, Annes M, Oliveira AS. Clinical and genetic basis of congenital myasthenic syndromes. Arq Neuropsiquiatr. 2016;74:750-60. 
25. Schmidt C, Abicht A, Krampfl K, Voss W, Stucka R, Mildner G, Petrova S, Schara U, Mortier W, Bufler J, Huebner A, Lochmüller H. Congenital myasthenic syndrome due to a novel missense mutation in the gene encoding choline acetyltransferase. Neuromuscul Disord. 2003;13:245-51.

26. Finlayson S, Morrow JM, Rodriguez Cruz PM, Sinclair CD, Fischmann A, Thornton JS, Knight S, Norbury R, White M, Al-Hajjar M, Carboni N, Jayawant S, Robb SA, Yousry TA, Beeson D, Palace J. Muscle magnetic resonance imaging in congenital myasthenic syndromes. Muscle Nerve. 2016;54:211-9.

27. Tan JS, Ambang T, Ahmad-Annuar A, Rajahram GS, Wong KT, Goh KJ. Congenital myasthenic syndrome due to novel CHAT mutations in an ethnic kadazandusun family. Muscle Nerve. 2016;53:822-6.

28. Schara U, Christen HJ, Durmus H, Hietala M, Krabetz K, Rodolico C, Schreiber G, Topaloglu H, Talim B, Voss W, Pihko H, Abicht A, Müller JS, Lochmüller H. Long-term follow-up in patients with congenital myasthenic syndrome due to CHAT mutations. Eur J Paediatr Neurol. 2010;14:326-33.

29. O'Grady GL, Verschuuren C, Yuen M, Webster R, Menezes M, Fock JM, Pride N, Best HA, Benavides Damm T, Turner C, Lek M, Engel AG, North KN, Clarke NF, MacArthur DG, Kamsteeg EJ, Cooper ST. Variants in SLC18A3, vesicular acetylcholine transporter, cause congenital myasthenic syndrome. Neurology. 2016;87:1442-8.

30. Shen XM, Selcen D, Brengman J, Engel AG. Mutant SNAP25B causes myasthenia, cortical hyperexcitability, ataxia, and intellectual disability. Neurology. 2014;83:2247-55.

31. Salpietro V, Lin W, Delle Vedove A, Storbeck M, Liu Y, Efthymiou S, Manole A, Wiethoff S, Ye Q, Saggar A, McElreavey K, Krishnakumar SS, SYNAPS Study Group, Pitt M, Bello OD, Rothman JE, Basel-Vanagaite L, Hubshman MW, Aharoni S, Manzur AY, Wirth B, Houlden H. Homozygous mutations in VAMP1 cause a presynaptic congenital myasthenic syndrome. Ann Neurol. 2017;81:597-603.

32. Whittaker RG, Herrmann DN, Bansagi B, Hasan BA, Lofra RM, Logigian EL, Sowden JE, Almodovar JL, Littleton JT, Zuchner S, Horvath R, Lochmüller H. Electrophysiologic features of SYT2 mutations causing a treatable neuromuscular syndrome. Neurology. 2015;85:1964-71.

33. Herrmann DN, Horvath R, Sowden JE, Gonzalez M, Sanchez-Mejias A, Guan Z, Whittaker RG, Almodovar JL, Lane M, Bansagi B, Pyle A, Boczonadi V, Lochmüller H, Griffin H, Chinnery PF, Lloyd TE, Littleton JT, Zuchner S. Synaptotagmin 2 mutations cause an autosomal-dominant form of lambertEaton myasthenic syndrome and nonprogressive motor neuropathy. Am J Hum Genet. 2014:95:332-9.

34. Xu J, Camacho M, Xu Y, Esser V, Liu X, Trimbuch T, Pan YZ, Ma C, Tomchick DR, Rosenmund C, Rizo J. Mechanistic insights into neurotransmitter release and presynaptic plasticity from the crystal structure of Munc13-1 C(1)C(2)BMUN. Elife. 2017 Feb 8;6. pii: e22567. doi: https://doi.org/10.7554/eLife.22567.

35. Engel AG. Congenital Myasthenic syndromes in 2018. Curr Neurol Neurosci Rep. 2018;18(8):46. https://doi.org/10.1007/s11910-018-0852-4.

36. Engel AG, Selcen D, Shen XM, Milone M, Harper CM. Loss of MUNC13-1 function causes microcephaly, cortical hyperexcitability, and fatal myasthenia. Neurol Genet. 2016;2(5):e105. https://doi.org/10.1212/NXG 0000000000000105.

37. Arredondo J, Lara M, Ng F, Gochez DA, Lee DC, Logia SP, Nguyen J, Maselli RA. COOH-terminal collagen Q (COLQ) mutants causing human deficiency of endplate acetylcholinesterase impair the interaction of ColQ with proteins of the basal lamina. Hum Genet. 2014;133:599-616.

38. Matlik HN, Milhem RM, Saadeldin IY, Al-Jaibeji HS, Al-Gazali L, Ali BR. Clinical and molecular analysis of a novel COLQ missense mutation causing congenital myasthenic syndrome in a Syrian family. Pediatr Neurol. 2014:51:165-9.

39. Mihaylova V, Müller JS, Vilchez JJ, Salih MA, Kabiraj MM, D'Amico A, Bertini E, Wölfle J, Schreiner F, Kurlemann G, Rasic VM, Siskova D, Colomer J, Herczegfalvi A, Fabriciova K, Weschke B, Scola R, Hoellen F, Schara U, Abicht A, Lochmüller $\mathrm{H}$. Clinical and molecular genetic findings in COLQ-mutant congenital myasthenic syndromes. Brain. 2008;131:747-59.

40. Wargon I, Richard P, Kuntzer T, Sternberg D, Nafissi S, Gaudon K, Lebail A, Bauche S, Hantaï D, Fournier E, Eymard B, Stojkovic T. Long-term follow-up of patients with congenital myasthenic syndrome caused by COLQ mutations. Neuromuscul Disord. 2012;22:318-24.

41. Al-Muhaizea MA, Al-Mobarak SB. COLQ-mutant congenital Myasthenic syndrome with microcephaly: a unique case with literature review. Transl Neurosci. 2017:8:65-9.

42. Al-Shahoumi R, Brady LI, Schwartzentruber J, Tarnopolsky MA. Two cases of congenital myasthenic syndrome with vocal cord paralysis. Neurology. 2015; $84: 1281-2$.
43. Duran GS, Uzunhan TA, Ekici B, Çıtak A, Aydınlı N, Çalışkan M. Severe scoliosis in a patient with COLQ mutation and congenital myasthenic syndrome: a clue for diagnosis. Acta Neurol Belg. 2013;113:531-2.

44. Schreiner F, Hoppenz M, Klaeren R, Reimann J, Woelfle J. Novel COLQ mutation 950delC in synaptic congenital myasthenic syndrome and symptomatic heterozygous relatives. Neuromuscul Disord. 2007;17:262-5.

45. Guo Y, Menezes MJ, Menezes MP, Liang J, Li D, Riley LG, Clarke NF, Andrews PI, Tian L, Webster R, Wang F, Liu X, Shen Y, Thorburn DR, Keating BJ, Engel A, Hakonarson H, Christodoulou J, Xu X. Delayed diagnosis of congenital myasthenia due to associated mitochondrial enzyme defect. Neuromuscul Disord. 2015:25:257-61.

46. Evangelista T, Hanna M, Lochmüller H. Congenital Myasthenic syndromes with predominant limb girdle weakness. J Neuromuscul Dis. 2015;2(suppl 2):S21-9.

47. Yeung WL, Lam CW, Ng PC. Intra-familial variation in clinical manifestations and response to ephedrine in siblings with congenital myasthenic syndrome caused by novel COLQ mutations. Dev Med Child Neurol. 2010;52:e243-4.

48. Padmanabha H, Saini AG, Sankhyan N, Singhi P. COLQ-related congenital Myasthenic syndrome and response to salbutamol therapy. J Clin Neuromuscul Dis. 2017;18:162-3.

49. Maselli RA, Ng JJ, Anderson JA, Cagney O, Arredondo J, Williams C, Wessel HB, Abdel-Hamid H, Wollmann RL. Mutations in LAMB2 causing a severe form of synaptic congenital myasthenic syndrome. J Med Genet. 2009;46: 203-8.

50. De Luca M, Crocco P, De Rango F, Passarino G, Rose G. Association of the Laminin, alpha 5 (LAMA5) rs4925386 with height and longevity in an elderly population from southern Italy. Mech Ageing Dev. 2016;155:55-9.

51. Maselli RA, Arredondo J, Vázquez J, Chong JX, University of Washington Center for Mendelian Genomics, Bamshad MJ, Nickerson DA, Lara M, Ng F, Lo VL, Pytel P, McDonald CM. Presynaptic congenital myasthenic syndrome with a homozygous sequence variant in LAMA5 combines myopia, facial tics, and failure of neuromuscular transmission. Am J Med Genet A. 2017; 173:2240-5.

52. Logan CV, Cossins J, Rodríguez Cruz PM, Parry DA, Maxwell S, MartínezMartínez P, Riepsaame J, Abdelhamed ZA, Lake AV, Moran M, Robb S, Chow G, Sewry C, Hopkins PM, Sheridan E, Jayawant S, Palace J, Johnson CA, Beeson D. Congenital Myasthenic syndrome type 19 is caused by mutations in COL13A1, encoding the atypical non-fibrillar collagen type XIII a1 chain. Am J Hum Genet. 2015;97:878-85.

53. Tei S, Ishii HT, Mitsuhashi H, Ishiura S. Antisense oligonucleotide-mediated exon skipping of CHRNA1 pre-mRNA as potential therapy for congenital Myasthenic syndromes. Biochem Biophys Res Commun. 2015;461:481-6.

54. Brugnoni R, Maggi L, Canioni E, Moroni I, Pantaleoni C, D'Arrigo S, Riva D, Cornelio F, Bernasconi P, Mantegazza R. Identification of previously unreported mutations in CHRNA1, CHRNE and RAPSN genes in three unrelated Italian patients with congenital myasthenic syndromes. J Neurol. 2010;257:1119-23.

55. Michalk A, Stricker S, Becker J, Rupps R, Pantzar T, Miertus J, Botta G, Naretto VG, Janetzki C, Yaqoob N, Ott CE, Seelow D, Wieczorek D, Fiebig B, Wirth B, Hoopmann M, Walther M, Körber F, Blankenburg M, Mundlos S, Heller R, Hoffmann K. Acetylcholine receptor pathway mutations explain various fetal akinesia deformation sequence disorders. Am J Hum Genet. 2008;82:464-76.

56. Shen XM, Okuno T, Milone M, Otsuka K, Takahashi K, Komaki H, Giles E, Ohno K, Engel AG. Mutations causing Slow-Channel myasthenia reveal that a valine ring in the channel pore of muscle AChR is optimized for stabilizing channel gating. Hum Mutat. 2016;37:1051-9.

57. Natera-de Benito D, Töpf A, Vilchez JJ, González-Quereda L, DomínguezCarral J, Díaz-Manera J, Ortez C, Bestué M, Gallano P, Dusl M, Abicht A, Müller JS, Senderek J, García-Ribes A, Muelas N, Evangelista T, Azuma Y, McMacken G, Paipa Merchan A, Rodríguez Cruz PM, Camacho A, Jiménez E, Miranda-Herrero MC, Santana-Artiles A, García-Campos O, Dominguez-Rubio R, Olivé M, Colomer J, Beeson D, Lochmüller H, Nascimento A. Molecular characterization of congenital myasthenic syndromes in Spain. Neuromuscul Disord 2017. pii: S0960-8966(17)30475-3.

58. Müller JS, Baumeister SK, Schara U, Cossins J, Krause S, von der Hagen M, Huebner A, Webster R, Beeson D, Lochmüller H, Abicht A. CHRND mutation causes a congenital myasthenic syndrome by impairing co-clustering of the acetylcholine receptor with rapsyn. Brain. 2006;129:2784-93.

59. Shen XM, Fukuda T, Ohno K, Sine SM, Engel AG. Congenital myasthenia-related AChR delta subunit mutation interferes with intersubunit communication essential for channel gating. J Clin Invest. 2008;118:1867-76. 
60. Sieb JP, Kraner S, Rauch M, Steinlein OK. Immature end-plates and utrophin deficiency in congenital myasthenic syndrome caused by epsilon-AChR subunit truncating mutations. Hum Genet. 2000;107:160-4.

61. Richard P, Gaudon K, Haddad H, Ammar AB, Genin E, Bauché S, PaturneauJouas M, Müller JS, Lochmüller H, Grid D, Hamri A, Nouioua S, Tazir M, Mayer M, Desnuelle C, Barois A, Chabrol B, Pouget J, Koenig J, GouiderKhouja N, Hentati F, Eymard B, Hantaï D. The CHRNE 1293insG founder mutation is a frequent cause of congenital myasthenia in North Africa. Neurology. 2008;71:1967-72.

62. Faber CG, Molenaar PC, Vles JS, Bonifati DM, Verschuuren JJ, van Doorn PA, Kuks JB, Wokke JH, Beeson D, De Baets M. AChR deficiency due to epsilonsubunit mutations: two common mutations in the Netherlands. J Neurol. 2009:256:1719-23.

63. Webster R, Maxwell S, Spearman H, Tai K, Beckstein O, Sansom M, Beeson D. A novel congenital myasthenic syndrome due to decreased acetylcholine receptor ion-channel conductance. Brain. 2012;135:1070-80.

64. Salih MA, Oystreck DT, Al-Faky YH, Kabiraj M, Omer MI, Subahi EM, Beeson D, Abu-Amero KK, Bosley TM. Congenital myasthenic syndrome due to homozygous CHRNE mutations: report of patients in Arabia. J Neuroophthalmol. 2011;31:42-7.

65. Shen XM, Brengman JM, Edvardson S, Sine SM, Engel AG. Highly fatal fastchannel syndrome caused by AChR $\varepsilon$ subunit mutation at the agonist binding site. Neurology. 2012;79:449-54.

66. Sadeh M, Shen XM, Engel AG. Beneficial effect of albuterol in congenital myasthenic syndrome with epsilon-subunit mutations. Muscle Nerve. 2011; 44:289-91.

67. Finlayson S, Palace J, Belaya K, Walls TJ, Norwood F, Burke G, Holton JL, Pascual-Pascual SI, Cossins J, Beeson D. Clinical features of congenital myasthenic syndrome due to mutations in DPAGT1. J Neurol Neurosurg Psychiatry. 2013:84:1119-25.

68. Hoffmann K, Muller JS, Stricker S, Megarbane A, Rajab A, Lindner TH, Cohen M, Chouery E, Adaimy L, Ghanem I, Delague V, Boltshauser E, Talim B, Horvath R, Robinson PN, Lochmüller H, Hübner C, Mundlos S. Escobar syndrome is a prenatal myasthenia caused by disruption of the acetylcholine receptor fetal gamma subunit. Am J Hum Genet. 2006;79:303-12.

69. Kariminejad A, Almadani N, Khoshaeen A, Olsson B, Moslemi AR, Tajshargh $H$. Truncating CHRNG mutations associated with interfamilial variability of the severity of the Escobar variant of multiple pterygium syndrome. BMC Genet. 2016;17:71. https://doi.org/10.1186/s12863-016-0382-5.

70. Müller JS, Herczegfalvi A, Vilchez JJ, Colomer J, Bachinski LL, Mihaylova V, Santos M, Schara U, Deschauer M, Shevell M, Poulin C, Dias A, Soudo A, Hietala M, Aärimaa T, Krahe R, Karcagi V, Huebner A, Beeson D, Abicht A Lochmüller $\mathrm{H}$. Phenotypical spectrum of DOK7 mutations in congenital myasthenic syndromes. Brain. 2007;130:1497-506.

71. Bergamin E, Hallock PT, Burden SJ, Hubbard SR. The cytoplasmic adaptor protein Dok7 activates the receptor tyrosine kinase MuSK via dimerization. Mol Cell. 2010;39:100-9.

72. Azuma Y, Töpf A, Evangelista T, Lorenzoni PJ, Roos A, Viana P, Inagaki H, Kurahashi $\mathrm{H}$, Lochmüller $\mathrm{H}$. Intragenic DOK7 deletion detected by wholegenome sequencing in congenital myasthenic syndromes. Neurol Genet. 2017 May 3:3(3):e152. https://doi.org/10.1212/NXG.0000000000000152.

73. Palace J, Lashley D, Newsom-Davis J, Cossins J, Maxwell S, Kennett R, Jayawant S, Yamanashi Y, Beeson D. Clinical features of the DOK7 neuromuscular junction synaptopathy. Brain. 2007;130:1507-15.

74. Jephson CG, Mills NA, Pitt MC, Beeson D, Aloysius A, Muntoni F, Robb SA, Bailey CM. Congenital stridor with feeding difficulty as a presenting symptom of Dok7 congenital myasthenic syndrome. Int J Pediatr Otorhinolaryngol. 2010;74:991-4.

75. Srour M, Bolduc V, Guergueltcheva V, Lochmüller H, Gendron D, Shevell ML, Poulin C, Mathieu J, Bouchard JP, Brais B. DOK7 mutations presenting as a proximal myopathy in French Canadians. Neuromuscul Disord. 2010;20:453-7.

76. Ben Ammar A, Petit F, Alexandri N, Gaudon K, Bauché S, Rouche A, Gras D, Fournier E, Koenig J, Stojkovic T, Lacour A, Petiot P, Zagnoli F, Viollet L, Pellegrini N, Orlikowski D, Lazaro L, Ferrer X, Stoltenburg G, Paturneau-Jouas M, Hentati F, Fardeau M, Sternberg D, Hantaï D, Richard $\mathrm{P}$, Eymard B. Phenotype genotype analysis in 15 patients presenting a congenital myasthenic syndrome due to mutations in DOK7. J Neurol. 2010;257:754-66.

77. Lashley D, Palace J, Jayawant S, Robb S, Beeson D. Ephedrine treatment in congenital myasthenic syndrome due to mutations in DOK7. Neurology. 2010;74:1517-23.
78. Schara U, Barisic N, Deschauer M, Lindberg C, Straub V, Strigl-Pill N, Wendt M, Abicht A, Müller JS, Lochmüller H. Ephedrine therapy in eight patients with congenital myasthenic syndrome due to DOK7 mutations. Neuromuscul Disord. 2009;19:828-32.

79. Bevilacqua JA, Lara M, Díaz J, Campero M, Vázquez J, Maselli RA. Congenital Myasthenic syndrome due to DOK7 mutations in a family from Chile. Eur J Transl Myol. 2017;27:6832.

80. Tsao CY. Effective treatment with albuterol in DOK7 congenital Myasthenic syndrome in children. Pediatr Neurol. 2016;54:85-7.

81. Luan $X$, Tian W, Cao L. Limb-girdle congenital myasthenic syndrome in a Chinese family with novel mutations in MUSK gene and literature review. Clin Neurol Neurosurg. 2016;150:41-5.

82. Giarrana ML, Joset P, Sticht H, Robb S, Steindl K, Rauch A, Klein A. A severe congenital myasthenic syndrome with "dropped head" caused by novel MUSK mutations. Muscle Nerve. 2015;52:668-73.

83. Gallenmüller C, Müller-Felber W, Dusl M, Stucka R, Guergueltcheva V, Blaschek A, von der Hagen M, Huebner A, Müller JS, Lochmüller H, Abicht A Salbutamol-responsive limb-girdle congenital myasthenic syndrome due to a novel missense mutation and heteroallelic deletion in MUSK. Neuromuscul Disord. 2014;24:31-5.

84. Maggi L, Brugnoni R, Scaioli V, Winden TL, Morandi L, Engel AG, Mantegazza $\mathrm{R}$, Bernasconi P. Marked phenotypic variability in two siblings with congenital myasthenic syndrome due to mutations in MUSK. J Neurol. 2013; [Epub ahead of print].

85. Maselli RA, Arredondo J, Cagney O, Ng JJ, Anderson JA, Williams C, Gerke BJ, Soliven B, Wollmann RL. Mutations in MUSK causing congenital myasthenic syndrome impair MuSK-Dok-7 interaction. Hum Mol Genet. 2010;19:2370-9.

86. O'Connor E, Töpf A, Müller JS, Cox D, Evangelista T, Colomer J, Abicht A, Senderek J, Hasselmann O, Yaramis A, Laval SH, Lochmüller H. Identification of mutations in the MYO9A gene in patients with congenital myasthenic syndrome. Brain. 2016;139:2143-53.

87. Karakaya M, Ceyhan-Birsoy O, Beggs AH, Topaloglu H. A novel missense variant in the AGRN gene; congenital Myasthenic syndrome presenting with head drop. J Clin Neuromuscul Dis. 2017;18:147-51.

88. Nicole $S$, Chaouch A, Torbergsen T, Bauché S, de Bruyckere E, Fontenille MJ, Horn MA, van Ghelue M, Løseth S, Issop Y, Cox D, Müller JS, Evangelista T, Stålberg E, loos C, Barois A, Brochier G, Sternberg D, Fournier E, Hantaï D, Abicht A, Dusl M, Laval SH, Griffin H, Eymard B, Lochmüller H. Agrin mutations lead to a congenital myasthenic syndrome with distal muscle weakness and atrophy. Brain. 2014;137:2429-43.

89. Kim N, Stiegler AL, Cameron TO, Hallock PT, Gomez AM, Huang JH, Hubbard SR, Dustin ML, Burden SJ. Lrp4 is a receptor for Agrin and forms a complex with MuSK. Cell. 2008;135:334-42.

90. Ohkawara B, Cabrera-Serrano M, Nakata T, Milone M, Asai N, Ito K, Ito M, Masuda A, Ito Y, Engel AG, Ohno K. LRP4 third $\beta$-propeller domain mutations cause novel congenital myasthenia by compromising agrin-mediated MuSK signaling in a position-specific manner. Hum Mol Genet. 2014;23:1856-68.

91. Hoshi T, Tezuka T, Yokoyama K, lemura S, Natsume T, Yamanashi Y. Mesdc2 plays a key role in cell-surface expression of Lrp4 and postsynaptic specialization in myotubes. FEBS Lett. 2013;587:3749-54.

92. Selcen D, Ohkawara B, Shen XM, McEvoy K, Ohno K, Engel AG. Impaired synaptic development, maintenance, and neuromuscular transmission in LRP4-related myasthenia. JAMA Neurol. 2015;72:889-96.

93. Régal L, Shen XM, Selcen D, Verhille C, Meulemans S, Creemers JW, Engel AG. PREPL deficiency with or without cystinuria causes a novel myasthenic syndrome. Neurology. 2014;82:1254-60.

94. Habbout K, Poulin H, Rivier F, Giuliano S, Sternberg D, Fontaine B, Eymard B, Morales RJ, Echenne B, King L, Hanna MG, Männikkö R, Chahine M, Nicole S, Bendahhou S. A recessive Nav1.4 mutation underlies congenital myasthenic syndrome with periodic paralysis. Neurology. 2016;86:161-9.

95. Arnold WD, Feldman DH, Ramirez S, He L, Kassar D, Quick A, Klassen $\mathrm{TL}$, Lara M, Nguyen J, Kissel JT, Lossin C, Maselli RA. Defective fast inactivation recovery of Nav 1.4 in congenital myasthenic syndrome. Ann Neurol. 2015;77:840-50.

96. Tsujino A, Maertens C, Ohno K, Shen XM, Fukuda T, Harper CM, Cannon SC, Engel AG. Myasthenic syndrome caused by mutation of the SCN4A sodium channel. Proc Natl Acad Sci U S A. 2003;100:7377-82.

97. Natera-de Benito D, Bestué M, Vilchez JJ, Evangelista T, Töpf A, García-Ribes A, Trujillo-Tiebas MJ, García-Hoyos M, Ortez C, Camacho A, Jiménez E, Dusl M, Abicht A, Lochmüller H, Colomer J, Nascimento A. Long-term follow-up 
in patients with congenital myasthenic syndrome due to RAPSN mutations. Neuromuscul Disord. 2016;26:153-9.

98. Maselli R, Dris H, Schnier J, Cockrell J, Wollmann R. Congenital myasthenic syndrome caused by two non-N88K rapsyn mutations. Clin Genet. 2007;72:63-5.

99. Milone M, Shen XM, Selcen D, Ohno K, Brengman J, lannaccone ST, Harper CM, Engel AG. Myasthenic syndrome due to defects in rapsyn: clinical and molecular findings in 39 patients. Neurology. 2009;73:228-35.

100. Lam CW, Wong KS, Leung HW, Law CY. Limb girdle myasthenia with digenic RAPSN and a novel disease gene AK9 mutations. Eur J Hum Genet. 2017;25:192-9.

101. Pavone P, Praticò AD, Pavone V, Falsaperla R. Congenital familial myasthenic syndromes: disease and course in an affected dizygotic twin pair. BMJ Case Rep 2013;2013. pii: bcr2012007651. doi: https://doi.org/10.1136/bcr-2012-007651.

102. Visser AC, Laughlin RS, Litchy WJ, Benarroch EE, Milone M. Rapsyn congenital myasthenic syndrome worsened by fluoxetine. Muscle Nerve. 2017;55:131-5.

103. Gentili A, Ansaloni S, Morello W, Cecini MT, Cordelli DM, Baroncini S. Diagnosis of congenital myasthenic syndrome with mutation of the RAPSN gene after general anaesthesia. Eur J Anaesthesiol. 2011;28:748-9.

104. Forrest K, Mellerio JE, Robb S, Dopping-Hepenstal PJ, McGrath JA, Liu L, Buk SJ, Al-Sarraj $\mathrm{S}$, Wraige $\mathrm{E}$, Jungbluth $\mathrm{H}$. Congenital muscular dystrophy, myasthenic symptoms and epidermolysis bullosa simplex (EBS) associated with mutations in the PLEC1 gene encoding plectin. Neuromuscul Disord. 2010;20:709-11.

105. Maselli RA, Arredondo J, Cagney O, Mozaffar T, Skinner S, Yousif S, Davis RR, Gregg JP, Sivak M, Konia TH, Thomas K, Wollmann RL. Congenital myasthenic syndrome associated with epidermolysis bullosa caused by homozygous mutations in PLEC1 and CHRNE. Clin Genet. 2011:80:444-51.

106. Selcen D, Juel VC, Hobson-Webb LD, Smith EC, Stickler DE, Bite AV, Ohno K, Engel AG. Myasthenic syndrome caused by plectinopathy. Neurology. 2011;76:327-36.

107. Chaouch A, Porcelli V, Cox D, Edvardson S, Scarcia P, De Grassi A, Pierri CL, Cossins J, Laval SH, Griffin H, Müller JS, Evangelista T, Töpf A, Abicht A, Huebner A, von der Hagen M, Bushby K, Straub V, Horvath R, Elpeleg O, Palace J, Senderek J, Beeson D, Palmieri L, Lochmüller H. Mutations in the mitochondrial citrate carrier SLC25A1 are associated with impaired neuromuscular transmission. J Neuromuscul Dis. 2014;1:75-90.

108. Cossins J, Belaya K, Hicks D, Salih MA, Finlayson S, Carboni N, Liu WW, Maxwell S, Zoltowska K, Farsani GT, Laval S, Seidhamed MZ, WGS500 Consortium, Donnelly P, Bentley D, SJ MG, Müller J, Palace J, Lochmüller H, Beeson D. Congenital myasthenic syndromes due to mutations in ALG2 and ALG14. Brain. 2013:136:944-56.

109. Belaya K, Rodríguez Cruz PM, Liu WW, Maxwell S, McGowan S, Farrugia ME, Petty R, Walls TJ, Sedghi M, Basiri K, Yue WW, Sarkozy A, Bertoli M, Pitt M, Kennett R, Schaefer A, Bushby K, Parton M, Lochmüller H, Palace J, Muntoni F, Beeson D. Mutations in GMPPB cause congenital myasthenic syndrome and bridge myasthenic disorders with dystroglycanopathies. Brain. 2015;138:2493-504.

110. Zoltowska K, Webster R, Finlayson S, Maxwell S, Cossins J, Müller J, Lochmüller H, Beeson D. Mutations in GFPT1 that underlie limb-girdle congenital myasthenic syndrome result in reduced cell-surface expression of muscle AChR. Hum Mol Genet. 2013;22:2905-13.

111. Dusl M, Senderek J, Müller JS, Vogel JG, Pertl A, Stucka R, Lochmüller H, David R, Abicht A. A 3'-UTR mutation creates a microRNA target site in the GFPT1 gene of patients with congenital myasthenic syndrome. Hum Mol Genet. 2015;24:3418-26.

112. Bauché S, Vellieux G, Sternberg D, Fontenille MJ, De Bruyckere E, Davoine CS, Brochier G, Messéant J, Wolf L, Fardeau M, Lacène E, Romero N, Koenig J, Fournier E, Hantaï D, Streichenberger N, Manel V, Lacour A, Nadaj-Pakleza A, Sukno S, Bouhour F, Laforêt P, Fontaine B, Strochlic L, Eymard B, Chevessier F, Stojkovic T, Nicole S. Mutations in GFPT1-related congenital myasthenic syndromes are associated with synaptic morphological defects and underlie a tubular aggregate myopathy with synaptopathy. J Neurol. 2017;264:1791-803.

113. Basiri K, Belaya K, Liu WW, Maxwell S, Sedghi M, Beeson D. Clinical features in a large Iranian family with a limb-girdle congenital myasthenic syndrome due to a mutation in DPAGT1. Neuromuscul Disord. 2013;23:469-72.

114. Guergueltcheva V, Müller JS, Dusl M, Senderek J, Oldfors A, Lindbergh C, Maxwell S, Colomer J, Mallebrera CJ, Nascimento A, Vilchez JJ, Muelas N, Kirschner J, Nafissi S, Kariminejad A, Nilipour Y, Bozorgmehr B, Najmabadi H, Rodolico C, Sieb JP, Schlotter B, Schoser B, Herrmann R, Voit T, Steinlein OK, Najafi A, Urtizberea A, Soler DM, Muntoni F, Hanna MG, Chaouch A, Straub V, Bushby K, Palace J, Beeson D, Abicht A, Lochmüller $\mathrm{H}$. Congenital myasthenic syndrome with tubular aggregates caused by GFPT1 mutations. J Neurol. 2012;259:838-50.

115. Maselli RA, Arredondo J, Nguyen J, Lara M, Ng F, Ngo M, Pham JM, Yi Q, Stajich JM, McDonald K, Hauser MA, Wollmann RL. Exome sequencing detection of two untranslated GFPT1 mutations in a family with limb-girdle myasthenia. Clin Genet. 2014:85:166-71.

116. Huh SY, Kim HS, Jang HJ, Park YE, Kim DS. Limb-girdle myasthenia with tubular aggregates associated with novel GFPT1 mutations. Muscle Nerve. 2012;46:600-4

117. Jensen BS, Willer T, Saade DN, Cox MO, Mozaffar T, Scavina M, Stefans VA, Winder TL, Campbell KP, Moore SA, Mathews KD. GMPPB-associated Dystroglycanopathy: emerging common variants with phenotype correlation. Hum Mutat. 2015;36:1159-63.

118. Luo S, Cai S, Maxwell S, Yue D, Zhu W, Qiao K, Zhu Z, Zhou L, Xi J, Lu J, Beeson D, Zhao C. Novel mutations in the C-terminal region of GMPPB causing limb-girdle muscular dystrophy overlapping with congenital myasthenic syndrome. Neuromuscul Disord. 2017;27:557-64.

119. Rodríguez Cruz PM, Belaya K, Basiri K, Sedghi M, Farrugia ME, Holton JL, Liu WW, Maxwell S, Petty R, Walls TJ, Kennett R, Pitt M, Sarkozy A, Parton M, Lochmüller H, Muntoni F, Palace J, Beeson D. Clinical features of the myasthenic syndrome arising from mutations in GMPPB. J Neurol Neurosurg Psychiatry. 2016;87:802-9.

120. Montagnese F, Klupp E, Karampinos DC, Biskup S, Gläser D, Kirschke JS, Schoser B. Two patients with GMPPB mutation: the overlapping phenotypes of limb-girdle myasthenic syndrome and limb-girdle muscular dystrophy dystroglycanopathy. Muscle Nerve. 2017;56:334-40.

121. Monies DM, Al-Hindi HN, Al-Muhaizea MA, Jaroudi DJ, Al-Younes B, Naim EA, Wakil SM, Meyer BF, Bohlega S. Clinical and pathological heterogeneity of a congenital disorder of glycosylation manifesting as a myasthenic/ myopathic syndrome. Neuromuscul Disord. 2014;24:353-9.

122. Schorling DC, Rost S, Lefeber DJ, Brady L, Müller CR, Korinthenberg R, Tarnopolsky M, Bönnemann CG, Rodenburg RJ, Bugiani M, Beytia M, Krüger M, van der Knaap M, Kirschner J. Early and lethal neurodegeneration with myasthenic and myopathic features: A new ALG14-CDG. Neurology 2017 pii: https://doi.org/10.1212/WNL.0000000000004234. doi: https://doi.org/10. 1212/WNL.0000000000004234.

123. Belaya K, Finlayson S, Slater CR, Cossins J, Liu WW, Maxwell S, McGowan SJ, Maslau S, Twigg SR, Walls TJ, Pascual Pascual SI, Palace J, Beeson D. Mutations in DPAGT1 cause a limb-girdle congenital myasthenic syndrome with tubular aggregates. Am J Hum Genet. 2012;91:193-201.

124. Selcen D, Shen XM, Brengman J, Li Y, Stans AA, Wieben E, Engel AG. DPAGT1 myasthenia and myopathy: genetic, phenotypic, and expression studies. Neurology. 2014;82:1822-30.

125. Klein A, Robb S, Rushing E, Liu WW, Belaya K, Beeson D. Congenital myasthenic syndrome caused by mutations in DPAGT. Neuromuscul Disord. 2015;25:253-6.

126. Rodríguez Cruz PM, Sewry C, Beeson D, Jayawant S, Squier W, McWilliam R, Palace J. Congenital myopathies with secondary neuromuscular transmission defects; a case report and review of the literature. Neuromuscul Disord. 2014;24:1103-10.

127. Baker K, Gordon SL, Grozeva D, van Kogelenberg M, Roberts NY, Pike M, Blair E, Hurles ME, Chong WK, Baldeweg T, Kurian MA, Boyd SG, Cousin MA, Raymond FL. Identification of a human synaptotagmin-1 mutation that perturbs synaptic vesicle cycling. J Clin Invest. 2015;125:1670-8.

128. Shields MC, Bowers MR, Fulcer MM, Bollig MK, Rock PJ, Sutton BR, VrailasMortimer AD, Lochmüller H, Whittaker RG, Horvath R, Reist NE. Drosophila studies support a role for a presynaptic synaptotagmin mutation in a human congenital myasthenic syndrome. PLoS One. 2017;12(9):e0184817. https://doi.org/10.1371/journal.pone.0184817.

129. Andreux F, Hantaï D, Eymard B. Congenital myasthenic syndromes: phenotypic expression and pathophysiological characterisation. Rev Neurol (Paris). 2004;160:163-76.

130. LoRusso SJ, lyadurai SJ. Decrement with high frequency repetitive nerve stimulation in a RAPSN congenital myasthenic syndrome. Muscle Nerve. 2017. https://doi.org/10.1002/mus.25995.

131. Caggiano S, Khirani S, Verrillo E, Barnerias C, Amaddeo A, Gitiaux C, Thierry B, Desguerre I, Cutrera R, Fauroux B. Sleep in infants with congenital myasthenic syndromes. Eur J Paediatr Neurol. 2017;21:842-51.

132. Chaouch A, Müller JS, Guergueltcheva V, Dusl M, Schara U, RakocevićStojanović V, Lindberg C, Scola RH, Werneck LC, Colomer J, Nascimento A, Vilchez JJ, Muelas N, Argov Z, Abicht A, Lochmüller H. A retrospective clinical study of the treatment of slow-channel congenital myasthenic syndrome. J Neurol. 2012;259:474-81.

133. Ohno K, Rahman MA, Nazim M, Nasrin F, Lin Y, Takeda Jl, Masuda A. Splicing regulation and dysregulation of cholinergic genes expressed at the neuromuscular junction. J Neurochem. 2017;142(suppl 2):64-72. 
134. Eymard B, Stojkovic T, Sternberg D, Richard P, Nicole S, Fournier E, Béhin A, Laforêt $P$, Servais $L$, Romero N, Fardeau M, Hantaï D. Membres du réseau national Syndromes Myasthéniques Congénitaux. Congenital myasthenic syndromes: difficulties in the diagnosis, course and prognosis, and therapy the French National Congenital Myasthenic Syndrome Network experience. Rev Neurol (Paris). 2013;169(suppl 1):S45-55.

135. Servais L, Baudoin H, Zehrouni K, Richard P, Sternberg D, Fournier E, Eymard B, Stojkovic T. Pregnancy in congenital myasthenic syndrome. J Neurol. 2013;260:815-9.

136. Ohno K, Brengman J, Tsujino A, Engel AG. Human endplate acetylcholinesterase deficiency caused by mutations in the collagen-like tail subunit (ColQ) of the asymmetric enzyme. Proc Natl Acad Sci U S A. 1998; 95:9654-9.

137. Ohno K, Sadeh M, Blatt I, Brengman JM, Engel AG. E-box mutations in the RAPSN promoter region in eight cases with congenital myasthenic syndrome. Hum Mol Genet. 2003;12:739-48.

138. Chevessier F, Faraut B, Ravel-Chapuis A, Richard P, Gaudon K, Bauché S, Prioleau C, Herbst R, Goillot E, loos C, Azulay JP, Attarian S, Leroy JP, Fournier E, Legay C, Schaeffer L, Koenig J, Fardeau M, Eymard B, Pouget J, Hantaï D. Towards the molecular elucidation of congenital myasthenic syndromes: identification of mutations in MuSK. Acta Myol. 2005;24:55-9.

139. Beeson D, Higuchi O, Palace J, Cossins J, Spearman H, Maxwell S, NewsomDavis J, Burke G, Fawcett P, Motomura M, Müller JS, Lochmüller H, Slater C, Vincent A, Yamanashi Y. Dok-7 mutations underlie a neuromuscular junction synaptopathy. Science. 2006;313:1975-8.

140. Huzé C, Bauché S, Richard P, Chevessier F, Goillot E, Gaudon K, Ben Ammar A, Chaboud A, Grosjean I, Lecuyer HA, Bernard V, Rouche A, Alexandri N, Kuntzer T, Fardeau M, Fournier E, Brancaccio A, Rüegg MA, Koenig J, Eymard $B$, Schaeffer L, Hantaï D. Identification of an agrin mutation that causes congenital myasthenia and affects synapse function. Am J Hum Genet. 2009:85:155-67.

141. Senderek J, Müller JS, Dusl M, Strom TM, Guergueltcheva V, Diepolder I, Laval SH, Maxwell S, Cossins J, Krause S, Muelas N, Vilchez JJ, Colomer J, Mallebrera CJ, Nascimento A, Nafissi S, Kariminejad A, Nilipour Y, Bozorgmehr B, Najmabadi H, Rodolico C, Sieb JP, Steinlein OK, Schlotter B, Schoser B, Kirschner J, Herrmann R, Voit T, Oldfors A, Lindbergh C, Urtizberea A, von der Hagen M, Hübner A, Palace J, Bushby K, Straub V, Beeson D, Abicht A, Lochmüller H. Hexosamine biosynthetic pathway mutations cause neuromuscular transmission defect. Am J Hum Genet. 2011;88:162-72.

142. Rodríguez Cruz PM, Palace J, Beeson D. The Neuromuscular Junction and Wide Heterogeneity of Congenital Myasthenic Syndromes. Int J Mol Sci 2018 ;19(6). pii: E1677. doi: https://doi.org/10.3390/ijms19061677.

143. Souza PV, Batistella GN, Lino VC, Pinto WB, Annes M, Oliveira AS. Clinical and genetic basis of congenital myasthenic syndromes. Arq Neuropsiquiatr 2016;74:750-760.

Ready to submit your research? Choose BMC and benefit from:

- fast, convenient online submission

- thorough peer review by experienced researchers in your field

- rapid publication on acceptance

- support for research data, including large and complex data types

- gold Open Access which fosters wider collaboration and increased citations

- maximum visibility for your research: over $100 \mathrm{M}$ website views per year

At BMC, research is always in progress.

Learn more biomedcentral.com/submissions 